\title{
Improvements of organic aerosol representations and their effects in large-scale atmospheric models
}

\author{
H. Tost ${ }^{1}$ and K. J. Pringle ${ }^{2}$ \\ ${ }^{1}$ Institut für Physik der Atmosphäre, Johannes Gutenberg Universität, Mainz, Germany \\ ${ }^{2}$ School of Earth and Environment, University of Leeds, Woodhouse Lane, Leeds, UK \\ Correspondence to: H. Tost (tosth@uni-mainz.de) \\ Received: 11 April 2012 - Published in Atmos. Chem. Phys. Discuss.: 20 April 2012 \\ Revised: 29 August 2012 - Accepted: 12 September 2012 - Published: 26 September 2012
}

\begin{abstract}
Organics dominate the composition of the atmospheric aerosol, especially in the fine mode, influencing some of its characteristics such as the hygroscopicity, which is of climatic relevance for the Earth system. This study targets an improvement in the description of organic aerosols suitable for large-scale modelling, making use of recent developments based on laboratory and field measurements. In addition to the organic mass and particle number distribution, the proposed method keeps track of the oxidation state of the aerosol based on the $\mathrm{OH}$ exposure time, describing some of its chemical characteristics. This study presents the application of the method in a global chemistry climate model, investigates the sensitivity to process formulations and emission assignments, provides a comparison with observations and analyses the climate impact.

Even though the organic aerosol mass distribution is hardly affected by the new formulation, it shows impacts (regionally of the order of $10 \%$ to $20 \%$ ) on parameters directly influencing climate via the direct and indirect aerosol effects. Furthermore, the global distribution of the organic $\mathrm{O}: \mathrm{C}$ ratio is analysed in detail, leading to different regimes in the oxidation state: low O:C ratios over the tropical continents due to small $\mathrm{OH}$ concentrations caused by $\mathrm{OH}$ depletion in chemical reactions, and enhanced oxidation states over the tropical oceans based on less $\mathrm{OH}$ scavengers and at high altitudes due to longer atmospheric residence time. Due to the relation between $\mathrm{O}: \mathrm{C}$ ratio and the aerosol hygroscopicity the ageing results in a more physically and chemically consistent description of aerosol water uptake by the organic aerosol. In
\end{abstract}

comparison with observations reasonable agreement for the $\mathrm{O}: \mathrm{C}$ ratio within the limits of a global model of the simulations is achieved.

\section{Introduction}

The composition of the atmospheric fine mode aerosol is dominated to a large extent by contributions of substances lumped under the term of organic carbon (e.g., Jimenez et al., 2009). These aerosol compounds affect the climate of the Earth system directly mainly by scattering and indirectly via indirect aerosol effects by altering cloud properties (e.g., IPCC core writing team, 2007). Furthermore, the chemical composition and formation of organic aerosol compounds can also impact the chemical composition of the atmosphere due modifications in the oxidation pathways and therefore the oxidation potential, but on the other hand are also directly impacted by the oxidation capacity of the atmosphere.

Especially in large-scale models describing the atmospheric aerosols, all of these compounds are treated together in a similar way, mostly lumped together as one compound per size category, named OC (organic carbon) or POM (particulate organic matter) (e.g., Textor et al., 2006). In reality, the actual compounds of this mixture are characterised by different oxidation states, and consequently different ratios of carbon to oxygen, and originate from various sources such as anthropogenic emissions, biomass burning or secondary aerosol formation from biogenic or anthropogenic volatile 
organic compounds (VOCs) which have been processed in the atmosphere reducing their volatility. The actual organic aerosol in models therefore should represent the complete mixture of all of these compounds including their varying properties. Even though some of these properties equilibrate quickly and can be described by mean characteristics (Andreae, 2009), others change over time. One of these properties is the oxidation state of the organic aerosol, described by the O:C ratio which is found to be a suitable metric to describe some of its chemical properties (Kroll et al., 2011).

Instead of treating all organic material in the particulate phase in only one compound, recently separate treatment of secondary organic aerosols (SOA) has become more common (e.g., Tsigaridis and Kanakidou, 2003; Kanakidou et al., 2005; O'Donnell et al., 2011). However, also this treatment does not provide an age spectrum, differentiating between aerosol particles being freshly formed or emitted or airborne for several days.

In addition to the "classical" approach of treating the organic aerosol, a new modelling approach has been developed in the recent years, namely the volatility basis set (VBS) (Robinson et al., 2007; Donahue et al., 2006) approach. VBS separates the organic aerosol into separate classes based on their volatility. This is used to describe both primary and secondary particles, however with this approach the computational load of the aerosol module component is substantially increased.

This increase has also been further amplified by equipping the VBS with a second dimension (Jimenez et al., 2009; Donahue et al., 2011, 2012): the ageing of organic aerosol particles. With this approach, chemical conversion can alter both the volatility of a compound and its oxidation state, represented by the O:C ratio. Even for regional studies conducted over a limited time frame, this concept was found too time consuming, that a more simplified approach is required (Shrivastava et al., 2011).

Based on observations, Jimenez et al. (2009) show that the $\mathrm{O}: \mathrm{C}$ ratio can be almost linearly translated into a value for the aerosol hygroscopicity $\kappa$ (Petters and Kreidenweis, 2007), and will therefore affect the water uptake of aerosols and their ability to act as cloud condensation nuclei (CCN). This linear relationship is the main basis of this study; due to some spread in the observations especially the offset for the linear regression is slightly vague, such that some of these uncertainties will propagate into the model simulations presented below.

Without doubt, the variety of organic aerosol compounds show a considerable range of hygroscopicity values (Suda et al., 2012). In addition to the different hygroscopicity values obtained for various compounds, Suda et al. (2012) also provided frequency spectra for individual species, depending on different oxidation states due to competition for oxidants. Lumping all of this information is required to transfer it to field measurements of ambient organic aerosol. For instance, Chang et al. (2010) conclude from their field stud- ies in Canada that the hygroscopicity can be described by a linear relationship with the observed $\mathrm{O}: \mathrm{C}$ ratio, in agreement with Jimenez et al. (2009). In their study the analysis is taken one step further to compare predicted and observed $\mathrm{CCN}$ numbers, based on the assumed and derived $\kappa$ values of the organic aerosol and concluded that the consideration of the $\mathrm{O}: \mathrm{C}$ ratio for the determination the hygroscopicity and total CCN numbers is relevant. However, also in this study it is stated that one value for $\kappa$ for a typical aged and one for the completely non-aged type of organic aerosol would be sufficient for climate modelling. On the other hand, this corresponds more or less to a decision whether the organic aerosol is hygroscopic or not, but does not consider the full spectrum of aged organic carbon aerosol with different water uptake potentials.

The here presented modelling study aims to analyse the impact of the processing of organic aerosol material by ageing on the aerosol distribution. A major goal is to quantify the importance of the characterisation of O:C ratios and hygroscopicity values on large scales to transfer knowledge from laboratory and field studies to the globally simulated context. Additionally, we present the global distribution of the O:C ratio in organic aerosols and corresponding organic aerosol hygroscopicity values for global scale climate which are according to our knowledge - not yet documented in the literature, and compare the simulated with observed values for various regions.

This study is structured as follows: The next section deals with the description of the applied model, the modifications required to investigate the research goals and the simulations that have been performed to analyse the impact of a description of the ageing of organic carbon aerosol. The results are discussed in Sect. 3 with focus on the total atmospheric budget (Sect. 3.1), the oxidation state of the aerosol (Sect. 3.2) and the impact on aerosol water uptake (Sect. 3.3). Furthermore, the impact of low molecular weight organics and their dissolution into aerosol water is addressed (Sect. 3.4). In a last step, the impact on climate relevant parameters, namely the aerosol optical thickness (Sect. 3.5) and on CCN numbers (Sect. 3.6) is analysed. This work is summarised and concludes in Sect. 4.

\section{Model description and simulation setup}

In this study the atmospheric chemistry climate model EMAC (ECHAM5/MESSy Atmospheric Chemistry) has been applied. EMAC model is a numerical chemistry and climate simulation system that includes sub-models describing tropospheric and middle atmosphere processes and their interaction with oceans, land and human influences (Jöckel et al., 2010). It uses the second version of the Modular Earth Submodel System (MESSy2) to link multi-institutional computer codes. The core atmospheric model is the 5th generation European Center Hamburg general circulation model 
(ECHAM5, Roeckner et al., 2006). For the present study we applied EMAC (ECHAM5 version 5.3.02, MESSy version $2.41)$ in the T42L31 resolution, i.e. with a spherical truncation of T42 (corresponding to a quadratic Gaussian grid of approx. 2.8 by 2.8 degrees in latitude and longitude) with 31 vertical hybrid pressure levels up to $10.0 \mathrm{hPa}$. The applied model setup comprised the submodels for radiation and large scale clouds (see Roeckner et al., 2003), convective clouds and tracer transport (Tost et al., 2010a), atmospheric gas phase chemistry (Sander et al., 2005), emissions (Kerkweg et al., 2006b; Tost et al., 2007b), dry deposition and aerosol sedimentation (Kerkweg et al., 2006a), scavenging and wet deposition (Tost et al., 2006, 2007a) and a representation of the atmospheric aerosol (Pringle et al. (2010a), described in detail below) and its radiative properties (Pozzer et al., 2012).

\subsection{Representation of the atmospheric aerosol}

The atmospheric aerosol in this study is parameterised using the MESSy aerosol submodel GMXe (Pringle et al., 2010a). GMXe combines treatment of the aerosol microphysics (in a similar way to the M7 model (Vignati et al., 2004)) with the aerosol thermodynamics model ISORROPIA II (Fountoukis and Nenes, 2007). The size distribution is described by four hydrophilic and three hydrophobic lognormal modes, with prognostic aerosol mass and number and a diagnosed mean radius.

Microphysical processes considered are the nucleation of new sulphuric acid aerosol particles, coagulation of aerosol particles, and exchange of particles between the modes, including the conversion of hydrophobic to hydrophilic modes via coating of the insoluble cores by soluble material. In addition to the coating material added to hydrophobic mode particles by coagulation, the condensation of hydrophilic material (determined from the thermodynamics) can also lead to the transition from hydrophobic to hydrophilic modes. These two process contribute to the microphysical ageing of organic carbon, i.e. they can lead to the transfer of aerosol from the hydrophobic to the hydrophilic modes and also to the transfer into other size classes.

Additionally, a transfer from hydrophobic to hydrophilic modes also occurs in case of cloud processing (by aerosol droplet coagulation processes), since it is assumed that the droplets represent a complete mixture of hydrophobic and hydrophilic material. Consequently, after evaporation the hydrophobic material is coated with hydrophilic material, such that the whole internally mixed aerosol particle must be considered as hydrophilic. Nevertheless, the hydrophobic material does not contribute significantly to the aerosol water uptake due to its low or zero hygroscopicity.

The aerosol compounds treated explicitly are $\mathrm{Na}^{+}, \mathrm{Cl}^{-}$, $\mathrm{NH}_{4}^{+}, \mathrm{SO}_{4}^{2-}, \mathrm{HSO}_{4}^{-}, \mathrm{NO}_{3}^{-}$and the bulk compounds of $\mathrm{OC}$, $\mathrm{BC}$, dust and a bulk sea salt (the fraction that is not described by $\mathrm{NaCl}$ or sea salt sulphate).
Compared to the GMXe, described in Pringle et al. (2010a), an updated version of the aerosol module is applied, which is equipped with a new internal flexible species structure, which allows for an arbitrary number of compounds to be used for the microphysical calculations, making use of tracer information provided by the TRACER structure of EMAC (Jöckel et al., 2008). Additionally, the water uptake of organic aerosol is calculated with the $\kappa$ approach (Petters and Kreidenweis, 2007). Furthermore, GMXe has been augmented by a more flexible scheme for emission flux assignment for aerosol compounds. Additionally, an emission parameterisation for marine organic aerosol has been implemented, using an approach following Vignati et al. (2010). This emission scheme represents the co-injection of marine organic compounds in submicron aerosol particles with sea salt based on bubble-bursting. The organic content of the sea water is estimated from climatological satellite data from the MODIS instrument (Esaias et al., 2002).

\subsubsection{Representation for the ageing of organic carbon}

To describe the time evolution of the organic aerosol, GMXe has been extended by a scheme which describes the chemical ageing of organic carbon. In this configuration the OC tracer is split up into an arbitrary number of species (6 for this study) which represent organic carbon but also take the oxidation state in terms of the O:C ratio into account. The scheme divides the $\mathrm{OC}$ tracer into the different species based on the $\mathrm{OH}$ exposure time (cf. Fig. 4b of Jimenez et al., 2009); the oxidation state of the bulk $\mathrm{OC}$ is calculated using the time varying $\mathrm{OH}$ concentration of the respective grid box. This is schematically displayed in Fig. 1.

The underlying chemical basis of this representation is that the organic compounds undergo a mixture of both heterogeneous in the aerosol phase and to a higher degree gas phase oxidation reactions in a series of re-evaporation and condensation processes (Donahue et al., 2006). The oxidation potential is described with the help of the most reactive oxidant of the troposphere $\mathrm{OH}$. Since in many oxidation reactions of organic compounds $\mathrm{OH}$ is also recycled (e.g., Taraborrelli et al., 2009, 2012), it is assumed that there is no net $\mathrm{OH}$ loss or consumption by the ageing process. This is the basis for the assumption that per each model time step in each grid box the $\mathrm{OH}$ concentration is treated as constant for this ageing process. Of course, the gas phase chemical reactions determine the actual time varying $\mathrm{OH}$ grid box mean value. An additional consideration of other oxidants, e.g. $\mathrm{O}_{3}$, $\mathrm{NO}_{3}$ or halogens is also possible with this approach, as the $\mathrm{OH}$ exposure time could be replaced by a total oxidant exposure time; however at present robust observations of the exposure time have only been published for $\mathrm{OH}$. When the $\mathrm{O}: \mathrm{C}$ ratio of a compound and its increment due to an additional exposure time calculated using the fitted function exceeds the threshold values of the individual tracers used in the model (as listed in Table 1) all the mass of this compound is 
Table 1. List of O:C ratios and corresponding $\kappa$ values for organic aerosol compounds.

\begin{tabular}{lrr}
\hline Species & O:C ratio & $\kappa$ value \\
\hline OC & 0.3 & 0.01 \\
WSOC1 & 0.38 & 0.05 \\
WSOC2 & 0.46 & 0.09 \\
WSOC3 & 0.54 & 0.13 \\
WSOC4 & 0.62 & 0.17 \\
WSOC5 & 0.7 & 0.21 \\
\hline
\end{tabular}

transferred to the tracer with the next higher oxidation state. In case of insufficient $\mathrm{OH}$ concentrations or too short an exposure time only a fraction of the mass of a tracer is converted to the next higher oxidised one using an interpolation algorithm that takes the $\mathrm{OH}$ exposure time increment and the interval to the current and the next higher oxidation state into account. This is done sequentially for all the OC and WSOC compounds in each mode; the WSOC compounds are treated such that at the beginning of each time step their oxidation state corresponds to the lower limit of the O:C interval represented by this compound. The abbreviation WSOC represent "water soluble organic carbon", as with higher number of the compounds, the $\mathrm{O}: \mathrm{C}$ ratio and therefore its hygroscopicity increases.

Since the O:C ratio is almost linear to the $\kappa$ value for organic aerosol according to measurements from all over the world (cf. Fig. 3 of Jimenez et al., 2009), a $\kappa$ value is assigned to each of the tracers with their corresponding O:C ratio according to the right axis of Fig. 1 as listed in Table 1 . This representation is a source of uncertainties in the modelling approach; however a shift in the offset or the slope does only to a minor degree change the total impact on the results. The total water uptake of organic carbon is determined as sum of the individual contributions from the organic aerosol tracers using the $\kappa$ approach and the ZSR (Stokes and Robinson, 1966) relation.

In the standard configuration of the scheme, this ageing process is only allowed for the organic carbon in the hydrophilic mode, but in one of the sensitivity tests, also the hydrophobic organic carbon can undergo this ageing with identical rates.

In contrast to the ageing processes described in the 2-D volatility basis set (VBS) (Donahue et al., 2011, 2012) as e.g. applied by Shrivastava et al. (2011) in the WRF-CHEM model, this approach requires fewer tracers and operations, making it computationally less expensive and suitable for global climate simulations. Only, the reduction of the VBS to a 2 species VBS by Shrivastava et al. (2011) uses a similar amount of compounds, but it has been developed and applied for the region of Mexico City only and its performance for other regions and hence other regimes of aerosol and oxidant concentrations is still under investigation. On the other hand,

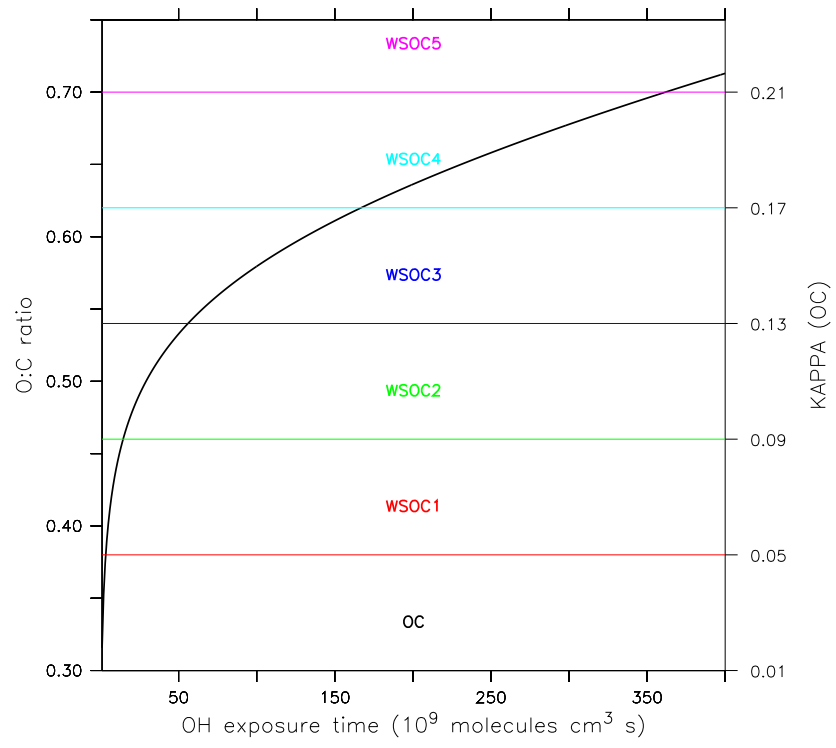

Fig. 1. Schematic curve of ageing of the organic carbon. The horizontal axis displays the $\mathrm{OH}$ exposure time, whereas the vertical axis show the $\mathrm{O}: \mathrm{C}$ ratio and corresponding $\kappa$ values. The horizontal coloured lines represent the threshold values for the $\mathrm{O}: \mathrm{C}$ ratio for the individual OC tracers.

the other feature of the VBS, namely the differentiation of the volatility and therefore the partitioning between gas and aerosol phase is not reproduced with the presented approach, showing the larger potential of the 2D-VBS. However, since in global climate models also the SOA is often described in a highly simplified way by the emission of primary emitted particles that have implicitly formed by the condensation of oxidised low volatility organic compounds originating from biogenic VOCs, the chosen approach does not limit the application for SOA organic carbon in climate studies.

Additionally, the fact that in general urban and remote, rural or stations downwind from pollution centers show similar characteristics for the organic aerosol $\mathrm{O}: \mathrm{C}$ ratio $(\mathrm{Ng}$ et al., 2010; Andreae, 2009) provides a reasonable basis for the presented approach.

\subsubsection{Non-equilibrium chemical processes in the aerosol}

For this work, GMXe has also been augmented by an explicit scheme for the calculation of non-equilibrium processes in the aqueous aerosol phase. For that purpose a set of chemical reactions describing the uptake and release in the aqueous aerosol phase according to a diffusion limited Henry's law, dissociation and recombination reactions and oxidation processes has been compiled. This set of equations is converted into a set of coupled differential equations by the KPP (Kinetic PreProcessor) software (Damian et al., 2002), including a differential equation solver using a Rosenbrock method of the third order with automatic time stepping control (Sandu et al., 1997). This approach offers similar possibilities as the 
scheme described by Kerkweg et al. (2007), but since it is treated decoupled from the gas phase chemistry due to the concept of operator splitting it is substantially cheaper from a computational point of view. Nevertheless, it is computationally more expensive than neglecting non-equilibrium processes (adding an additional 15 to $20 \%$ of computation time) and is therefore more suitable for process research than longterm climate studies. Note, that this extension is used in addition to aqueous phase chemistry processes in the cloud and precipitation phase, which is e.g. responsible for the dominant oxidation of $\mathrm{SO}_{2}$ to sulphate.

With the help of this tool the uptake and dissociation of low molecular weight organic compounds, e.g. formaldehyde ( $\mathrm{HCHO})$, formic acid $(\mathrm{HCOOH})$, acetic acid $\left(\mathrm{CH}_{3} \mathrm{COOH}\right)$ is taken into account. However, since the scheme calculates the uptake of these species into the aqueous phase of the aerosol, these compounds are currently not considered for aerosol hygroscopicity and water uptake calculations, but they do contribute to the total aerosol mass and participate in all aerosol microphysical processes. Furthermore, it provides opportunities to explicitly calculate oxidation reactions in the aerosol phase for organic and inorganic compounds, e.g. glyoxal production or $\mathrm{SO}_{2}$ oxidation in the aerosol phase (Tost et al., $2010 b)$. In the current configuration only inorganic and organic chemistry of low molecular weight organics (up to $\mathrm{C} 2$ compounds) is taken into account, but the scheme is capable of a comprehensive aqueous phase chemistry mechanism of reactions taking place in the aerosol phase (e.g. the CAPRAM mechanism, Herrmann et al., 2005).

\subsection{Simulation setup}

For this study five simulations have been performed. All of them span a period of 2 years, with the data from the first year used as spin-up and not taken into account for the analysis. The meteorological conditions are calculated in a free running climatological mode, with climatological (years 1995-2005) sea surface temperatures originating from the AMIPII database (Taylor et al., 2000). Greenhouse gas concentrations for the year 2000 have been applied and are nudged towards the observations. The emission data base for gaseous compounds are the IPCC-AR5 emissions for the year 2000 (Lamarque et al., 2010). Biomass burning emissions for gaseous compounds are taken from the GFEDv3.1 inventory (van der Werf et al., 2010). Aerosol emissions are from the AEROCOM data base, also representative for the year 2000, including also sea salt and mineral dust emissions (Dentener et al., 2006). The contribution of OC emissions are from fossil and bio-fuel burning, biogenic sources (representing SOA) and biomass burning. Additionally, also volcanic emissions of $\mathrm{SO}_{2}$ are taken from the Dentener et al. (2006) data base.

Even though the aerosol optical properties and their CCN potential are calculated, the actual radiation and cloud interactions with the aerosol are excluded (as well as chem- ical feedback) thus the meteorology is absolutely identical all simulations, which allows a direct comparison of the data sets from the individual simulations without taking the interannual variability or variations in the transport patterns into account. Instead, for aerosol radiation effects an aerosol climatology and for cloud effects fixed cloud droplet and ice crystal numbers are assumed.

The five simulation are summarised in the following section:

1. No-Ageing: In this simulation the chemical ageing of organic carbon is ignored, and it can serve as a standard aerosol simulation (comparable to the setup presented in Pringle et al., 2010b).

2. Ageing- $L O$ : In this simulation the chemical ageing of organic carbon is taken into account. All hydrophilic organic carbon is emitted into the compound with the lowest O:C ratio, representing an almost hydrophobic particle which increases its hygroscopicity only via the chemical ageing. This should be represented by the name "LO" meaning "Low Oxidation state".

3. Ageing-BG: This setup, named according to the "Best Guess" of the emission attribution, is similar to the Ageing- $L O$ case, except for a different assignment of the hydrophilic organic carbon emissions, i.e. $10 \%$ of the total hydrophilic SOA emissions are emitted in the lowest O:C class, $15 \%$ in the WSOC1, $20 \%$ in WSOC2 and $5 \%$ in WSOC3 each for Aitken and accumulation mode, respectively. Similarly the hydrophilic fraction of the biomass burning emissions is assigned with $20 \%$, $30 \%, 40 \%$ and $10 \%$ into the Aitken mode, respectively. In addition the hydrophilic emissions from marine organics are also emitted with the same fractions into the accumulation mode. This emission assignment has been the result of sensitivity tests, but showed the "best" agreement of the simulated O:C ratio with a few selected measurement campaigns, e.g. AMAZE (Martin et al., 2010) and some of the results presented in Fig. 4 as well as comparing the $\mathrm{OC}$ atmospheric mixing ratios with measurement stations (similar to Pringle et al., 2010a).

4. Aerchem: This setup is identical to the Ageing-BG configuration, except for the additional treatment of dissolution and non-equilibrium chemistry, described by the sub-submodel "Aerchem" (Sect. 2.1.2).

5. Insol: This setup has identical emission allocation as Ageing- $B G$, but in addition it allows chemical ageing to also occur for the hydrophobic material at the same rates as described in Sect. 2.1.1. In the hydrophobic aerosol the chemical conversion of the organic material results in more hydrophilic matter such that the aged organic aerosol is transferred into the hydrophilic modes, i.e. this process represents another pathway for 
hydrophobic organic aerosols to be transferred into the hydrophilic modes besides the above mentioned aerosol microphysical ageing and cloud processing.

\section{Results and discussion}

\subsection{Global budget of organic carbon aerosol compounds}

To analyse the impact of the chemical ageing process, the global atmospheric burden of the organic carbon aerosol compounds is displayed in Fig. 2 on a logarithmic scale. The blue bars represent the simulation without chemical ageing, the red bar the Ageing- $L O$ case, the yellow the Ageing-BG, the green the results from the Aerchem and the brown the Insol simulation. Except for the Insol case, the total organic carbon atmospheric burden in all modes is similar, independent of the considered ageing and the emission redistribution. For the hydrophobic Aitken mode OC, all simulations except Insol maintain a similar burden since the chemical ageing only indirectly affects the hydrophobic mode via changes in the size in the hydrophilic modes, which can subsequently effect the aerosol microphysics. On the other hand, since in the Insol configuration the $\mathrm{OC}_{\mathrm{ki}}$ is directly modified by both the chemical and the microphysical ageing (allowing a faster transformation into the hydrophilic mode) its burden is substantially reduced (almost up to $80 \%$ ).

For the hydrophilic Aitken mode, the differences in the burden mainly originate from the chemical ageing and the attribution of the emissions, e.g. since less OC mass is directly emitted in the $\mathrm{OC}_{\mathrm{ks}}$ tracer in the Ageing-BG simulation, but into species representing higher $\mathrm{O}: \mathrm{C}$ ratios, the burden of $\mathrm{OC}_{\mathrm{ks}}$ is lower than in the Ageing- $L O$ simulation. The difference between the No-Ageing and the Ageing-LO simulation originates mostly from the chemical ageing itself. Differences between Ageing-BG and Aerchem must be attributed to the modified size distribution due to the uptake of additional compounds in the Aerchem simulation, but they are negligibly small. The most prominent differences occur in the Insol simulation representing a reduction of almost $100 \%$. The first reason is the emission redistribution similar to the Ageing- $B G$ setup, but as seen for the latter setup this can only account for a decrease of half an order of magnitude. The dominant difference is due to the chemical ageing of the hydrophobic material. This conversion process occurs at a faster rate than the conversion via the microphysical processes of coagulation and coating by hydrophilic material. However, adding material from the hydrophobic to the hydrophilic mode also represents a growth mechanism, such that the organic material is quickly shifted into the accumulation mode. Additionally, due to the rate of change in the oxidation state (i.e. the "slope" of the graph in Fig. 1) the increase in the $\mathrm{O}: \mathrm{C}$ ratio is rapid for the lower O:C categories and then subsequently slows down. Consequently, the material from $\mathrm{OC}_{\mathrm{ki}}$ is not converted to $\mathrm{OC}_{\mathrm{ks}}$, but to one of the $\mathrm{WSOC}_{\mathrm{ks}}$ compounds. One additional aspect to consider is that during the chemical ageing the particles also undergo microphysical aerosol processes, such that for most OC compounds the mass is quickly shifted from the Aitken to the accumulation mode into one of the $\mathrm{WSOC}_{\mathrm{as}}$ species. In addition, the ageing increases the $\mathrm{CCN}$ potential of the fine mode organic aerosol such that nucleation scavenging becomes more efficient, and hence causes a more efficient removal process for organic carbon aerosol, compared to the other scenarios. This leads to an overall reduction of Aitken mode OC (depicted in the SUM column) of approx. $50 \%$ for the Insol simulation.

In principle the same processes also explain the differences in the accumulation mode mass distribution, again with the Insol simulation showing substantially reduced burden (reduction of $\approx 20 \%$ ). For the lower O:C ratio tracers the burden is even higher in this simulation due to the transfer of aged material that originates from both the hydrophobic and hydrophilic Aitken modes. For the three simulations in which the chemical ageing is only allowed for the hydrophilic modes, there is hardly any difference for the higher $\mathrm{O}: \mathrm{C}$ ratio tracers, whereas for the lower O:C ratio compounds the emission redistribution both in the Aitken and in the accumulation mode contribute to the differences.

For the coarse mode the Insol simulation does not a show reduced burden in the total: a reduced atmospheric load is found for the un-aged compounds but for the other compounds the burden is even increased. This is due to the more efficient ageing and the shift into the largest particle size representation via cloud processing with respect to the total organic aerosol mass before the aerosol loss processes remove the organic carbon aerosol mass from the atmosphere. Due to the enhanced emissions at higher O:C ratio in the Ageing- $B G$, Aerchem and Insol simulation, the burden of the tracers representing higher $\mathrm{O}: \mathrm{C}$ ratio are slightly enhanced compared to the Ageing- $L O$ case.

Note, that there is hardly any difference in the total OC mass in the case without chemical ageing compared to any of the sensitivity tests with the exception of the Insol scenario. This shows - as for the other modes - that the ageing process itself hardly disturbs the global mass distribution (except for the Insol case, due to the additional transfer to the hydrophilic mode). A comparison with observations as shown in Pringle et al. (2010a) is therefore hardly affected and shows a similar agreement (therefore not repeated in this manuscript). The respective surface mixing ratios are presented in Fig. 2 of the Supplement. Furthermore, a comparison of the OC column burdens for the five simulations is presented in Fig. 1 of the Supplement; this shows only very small deviations between the different scenarios.

\subsection{O:C ratio and $\kappa$ value}

In addition to the global mass in each tracer representing the oxidation state of the organic aerosol via the $\mathrm{O}: \mathrm{C}$ ratio, the 


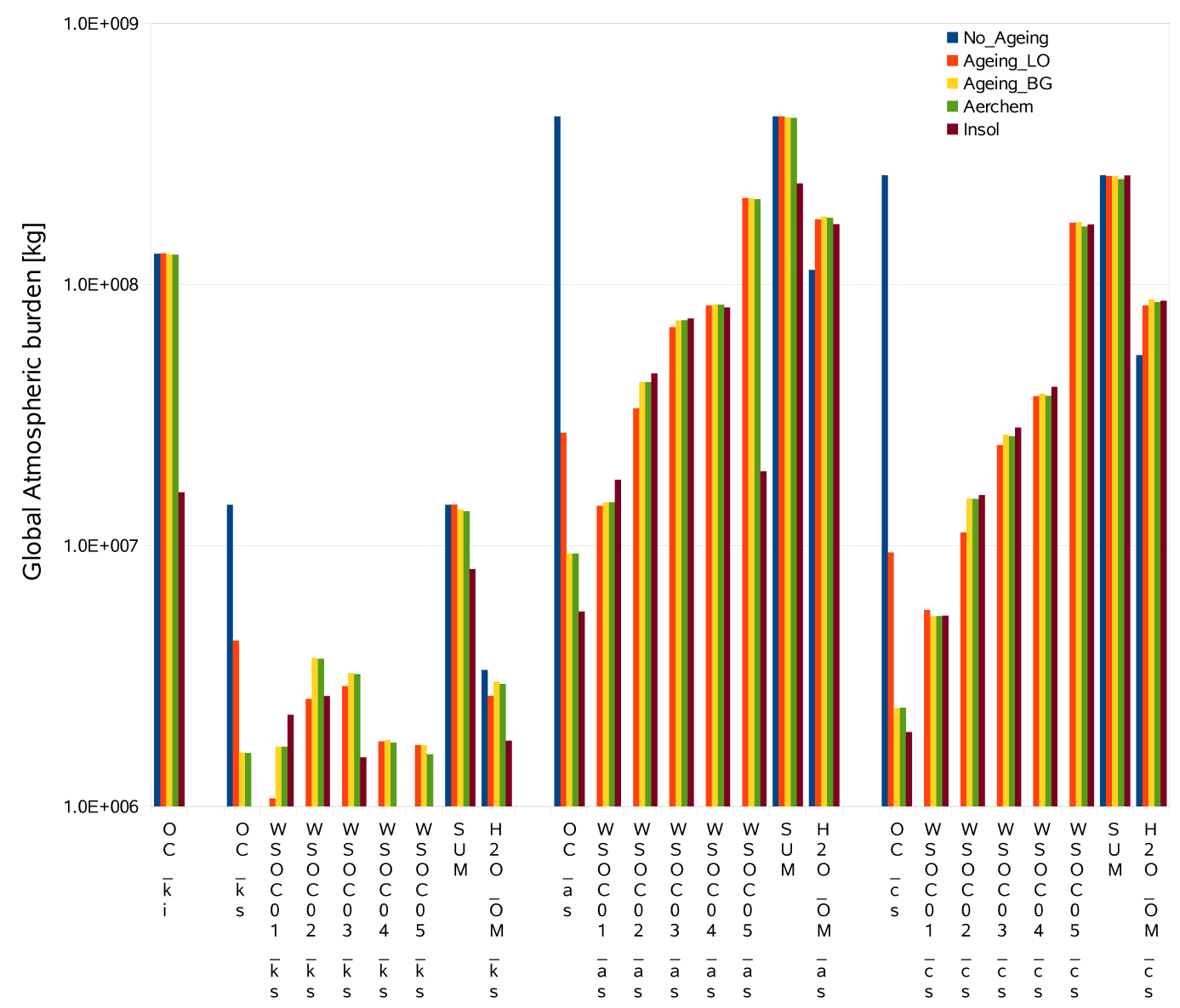

Fig. 2. Global atmospheric burden in $\mathrm{kg}$ (using a molar mass of 12, representing the carbon in the OC compounds) of the organic carbon aerosol compounds in all modes. Additionally the sum per mode, and the amount of aerosol water attached to the organic carbon are shown. The different colours denote the simulations. Note the logarithmic scale for the mass. The abbreviations " $k$ ", "a" and "c" denote the Aitken, accumulation and coarse mode respectively, whereas the letters "i" and "s" denote the insoluble =hydrophobic and soluble =hydrophilic characteristics of the modes.

geographic distributions of the oxidation state are analysed. Since in the No-Ageing simulation chemical ageing is not allowed to occur, the $\mathrm{O}: \mathrm{C}$ ratio is constant, and we assume a typical $\kappa$ value for organic carbon $\left(\kappa_{\mathrm{OC}}\right.$ of 0.1 (e.g., Pringle et al., 2010b; Wex et al., 2009; Pöschl et al., 2010)), thus the corresponding $\mathrm{O}: \mathrm{C}$ ratio is approximately 0.48 , according to the setup definition in Table 1. For the other simulations, a mean $\mathrm{O}: \mathrm{C}$ ratio of the organic aerosol is calculated from the $\mathrm{O}: \mathrm{C}$ ratios of the individual tracers as defined in Table 1 and the mixture of the individual tracer mixing ratio resulting in a weighted mean $\mathrm{O}: \mathrm{C}$ ratio for each model grid box. Detailed figures, describing the contributions of the individual OC tracers to the total organic carbon in each mode are shown in Figs. 4-15 of the Supplement.

Figure 3 shows in panel (a) the annual mean O:C ratio for the Ageing- $B G$ simulation at the surface. The geographic pattern is characterised by lower O:C ratios in the mid-latitude storm tracks on both hemispheres with lowest values in the Southern Hemisphere. Due to the low $\mathrm{OH}$ levels in this re- gion (displayed in Fig. 3 of the Supplement) the oxidising capacity of the atmosphere is low, resulting only in a slow, inefficient chemical ageing process. Towards the tropics with higher $\mathrm{OH}$ levels, the $\mathrm{O}: \mathrm{C}$ ratio increases, especially over the oceans and in other regions without pollutants competing for oxidants (e.g. the Sahara).

Over the tropical rain forests the mean $\mathrm{O}: \mathrm{C}$ ratio at the surface is around 0.48 in Amazonia and more than 0.5 in Central Africa. This is caused by the balance of high $\mathrm{OH}$ formation rates, but substantial $\mathrm{OH}$ depletion by other compounds, e.g. isoprene. This agrees with observations, e.g. Pöschl et al. (2010) report a mean value of 0.44 for the AMAZE-08 campaign in the Amazonian rain forest, but also with laboratory experiments (e.g., Hallquist et al. (2009), and references therein). However, it should be noted, that the recently found $\mathrm{OH}$ recycling over the tropical rain forest (e.g., Lelieveld et al., 2008; Taraborrelli et al., 2009) is not included in these model simulations, which could potentially lead to even higher simulated O:C ratios; on the other hand, 
"Ageing-BG" simulation

a) Surface O:C ratio

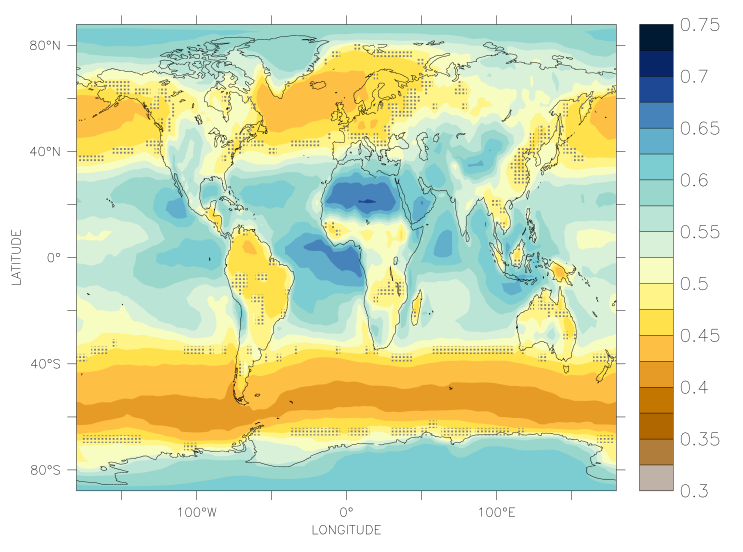

b) Zonal average $\mathrm{O}: \mathrm{C}$ ratio

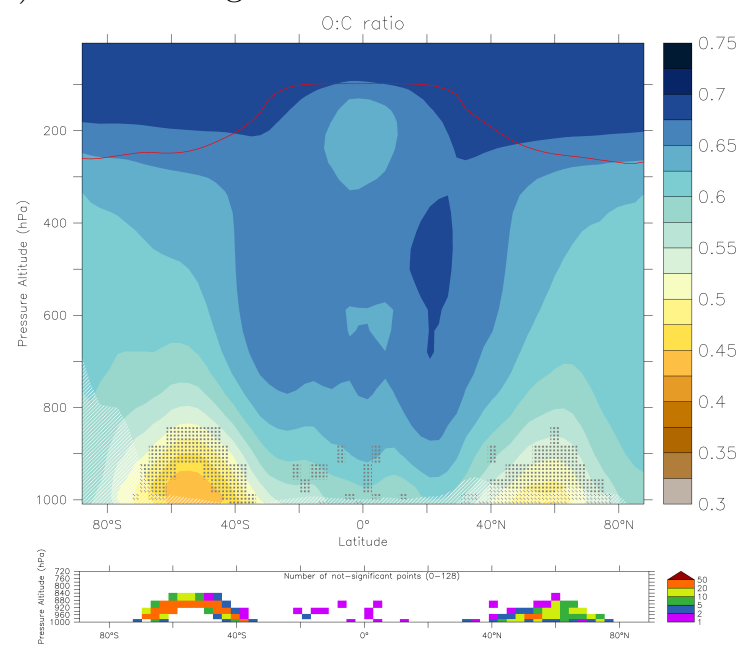

Relative difference: ( "Ageing-LO" - "Ageing-BG")/ "Ageing-BG" * 100

c) Surface O:C ratio difference

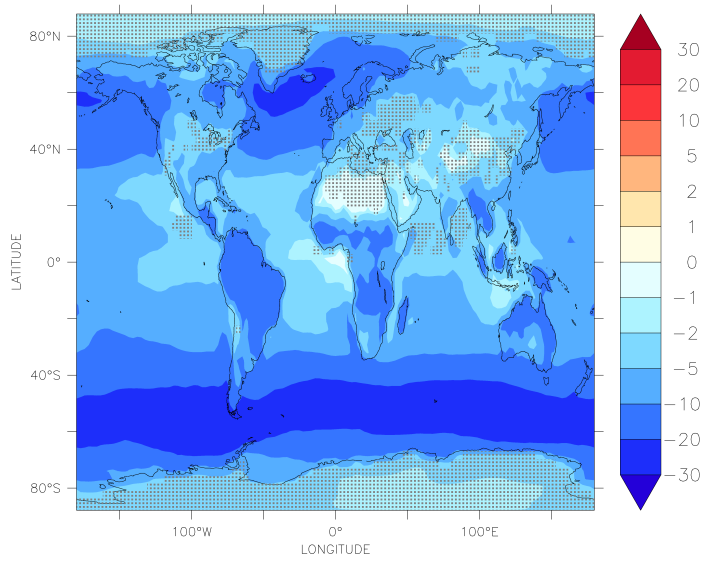

d) Zonal average O:C ratio difference

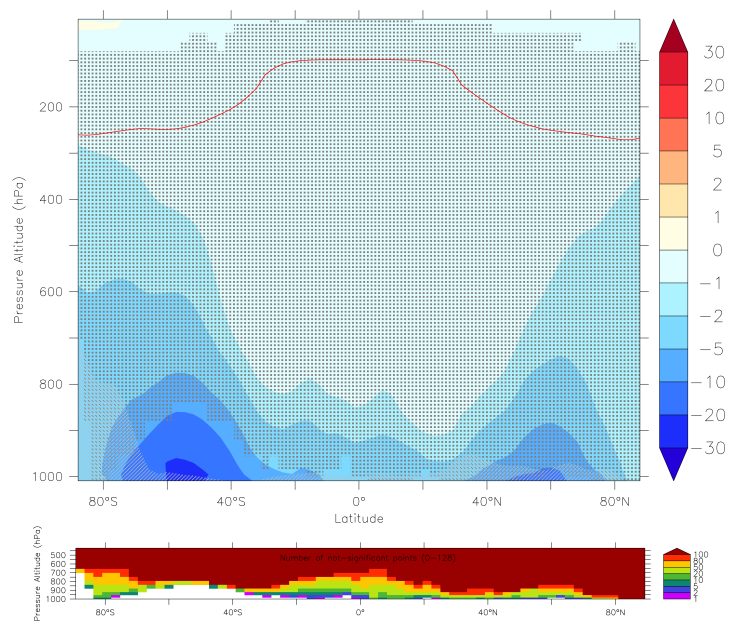

Fig. 3. Annual averages of the O:C ratio at the surface (panel a) and in the zonal average (panel b) for the Ageing-BG simulation. The dotted regions are those in which the difference to the constant $\mathrm{O}: \mathrm{C}$ ratio of the reference simulations is of a low statistical significance. The grey shaded area represents the zonal average orography, indicating less data points in these regions. The lower panel in this graph determines the number of points with differences of low significance. The red line represents the mean tropopause level. The lower panels (c, d) of the figure show the relative differences (in \%) for surface (c) and zonal average (d) between the Ageing-LO simulation and the Ageing-BG setup. Again the black dotted regions mark regions of low statistical significance for the differences between the two simulations, and the number of points of low significance is displayed in the lower panel.

this could be balanced by a different assignment of the emissions into lower O:C ratio tracers (like an intermediate between the Ageing- $L O$ and Ageing-BG scenarios).

Comparing the simulation results with other modelling studies, e.g. Shrivastava et al. (2011) using the 2-D VBS and a simplified version of it, a strong gradient (their Fig. 5) in the simulated $\mathrm{O}: \mathrm{C}$ ratio from the continental aerosol to the ocean over Mexico is analysed. Time resolved aerosol mass spectrometer measurements and the model simulations presented by Shrivastava et al. (2011) show varying values with a mean value of around 0.35 to 0.4 for Mexico City, but values of more than 0.6 over the ocean. Even though the values 
for Central Mexico of our model simulations slightly exceed the low observed values (with O:C ratios of 0.425 to 0.45 ), potentially due to an underestimation of the anthropogenic pollutants forming SOA and due to the large grid box of a global model, the gradient towards the ocean is nevertheless similarly captured with simulated values of approx. 0.6.

The variability (based on the 5 hourly output interval resulting in a full diurnal cycle after 5 days) in the $\mathrm{O}: \mathrm{C}$ ratio is relatively low (in terms of the standard deviation of the mean $\mathrm{O}: \mathrm{C}$ ratio value), such that in a comparison with the constant $\mathrm{O}: \mathrm{C}$ value from the No-Ageing simulation the difference between the simulations is in most regions statistically significantly different from zero (which is used as null hypothesis) with respect to an unpaired z-test and a $90 \%$ confidence interval, except for the black dotted areas in Fig. 3a. This measure for the statistical significance between two simulations is applied throughout the whole manuscript. This means that the spatial variability of the $\mathrm{O}: \mathrm{C}$ ratio is far from being constant, thus with a constant representation of the $\mathrm{O}: \mathrm{C}$ ratio and consequently a constant $\kappa$ value, spatial phenomena cannot be captured accurately.

Panel (b) of Fig. 3 shows the vertical distribution of the annual average zonal mean O:C ratio. Lowest values are obtained in the mid-latitudes over the oceans, as already described above. However, with increasing altitude the O:C ratio constantly increases. This is due to the fact that there is less competition for oxidants at the elevated altitude, i.e. therefore higher $\mathrm{OH}$ levels (see also the Supplement). Another even more important aspect is that, except for rapid transport by deep convection, the organic carbon aerosol requires a relatively long time to reach higher altitude. Since the ageing is a function of the $\mathrm{OH}$ exposure time, the $\mathrm{O}: \mathrm{C}$ ratio also increases with extended atmospheric residence time. This agrees with the observations shown in Shrivastava et al. (2011), that at elevated altitude, i.e. in aircraft measurements, the O:C ratio can be substantially enhanced. Upper tropospheric aerosol is especially highly oxidised. This also agrees with the results from Schmale et al. (2011), who found that organic aerosol in the polar upper troposphere is close to the maximum oxidation level, even exceeding the maximum obtained in the simulations. In this work the uppermost class of O:C ratio represented by the WSOC5 tracer has an O:C ratio value of 0.7 thus a higher value cannot be obtained with this setup, even if all organic aerosol were to have undergone complete ageing. It is clear from the zonal mean plot that, in line with the surface fields, most values are significantly different from the constant value of the reference simulation; the number of data points contributing to the regions of low significance are shown in lower graph of this panel (with a potential maximum value of 128 points, resulting from the zonal average of the model resolution).

While there are large changes between the No-Ageing and the Ageing- $B G$ scenarios due to the introduction of the chemical OC aging, the changes between the other scenarios (which all include chemical ageing) are more subtle; they reflect deviations due to the uncertainty in the best way to represent the aging. In the following sections the Ageing- $B G$ simulation is chosen as a reference for difference plots, as this gives us a "best guess" baseline simulation. This allows us to examine the impact of different aging assumptions on the global distribution of O:C.

As stated in Sect. 2.2, in the Ageing-BG scenario the emitted $\mathrm{OC}$ is divided between different $\mathrm{O}: \mathrm{C}$ categories, but this division of aerosol between $\mathrm{O}: \mathrm{C}$ categories is uncertain, thus in this section we compare it to the sensitivity scenario in which all hydrophilic OC is emitted into the lowest O:C category (Ageing- $L O$ ). The lower panels of Fig. 3 show the relative difference of the Ageing- $L O$ to the Ageing- $B G$ simulation: the left panel shows the surface and the right the zonal average distribution. The emission of all OC into the lowest $\mathrm{O}: \mathrm{C}$ ratio tracer leads to a reduction of the simulated O:C ratio of up to $30 \%$ in the Southern Ocean. Also the tropical rainforests, which have high organic aerosol emissions and surface mixing ratios, are subject to a substantial reduction of up to $20 \%$ in the $\mathrm{O}: \mathrm{C}$ ratio. The anthropogenic OC emissions in East Asia are not affected by the change in the distribution of the hydrophilic OC emissions as they are mostly emitted into the hydrophobic mode. For this reason, the differences in these regions are small and not statistically significant. Since the chemical ageing affects both simulations similarly, the oxidation capacity of the atmosphere cannot make up for the $\mathrm{O}: \mathrm{C}$ ratio difference at the emission, thus near the surface this characteristic is maintained for most of the aerosol lifetime. However, at higher altitudes, the differences quickly converge towards zero, i.e. the ageing of OC above the boundary layer, which is important due to the longer atmospheric residence time, is efficient enough to equilibrate the $\mathrm{O}: \mathrm{C}$ ratio. However, the combination of boundary layer mixing, shallow and deep convection and large-scale lifting make it impossible to determine the time scales for this result. Nevertheless, on average air masses are mixed within 2 days sufficiently well, that is time period represents a rough lower limit estimate for such an equilibrium time. Therefore, at higher altitudes there is little sensitivity to the emission assumptions and the $\mathrm{O}: \mathrm{C}$ ratio is controlled mainly by the $\mathrm{OH}$ mixing ratios. This is even true in the tropics where the two simulations differ more significantly, i.e. fewer points are of "low significance" but the differences in the O:C ratio nevertheless remain almost negligible. This can also partly be explained with the gradient of the ageing curve in Fig. 1, which shows a quick response to changes for low $\mathrm{O}: \mathrm{C}$ ratios and slower impact for more oxidised compounds.

The difference plots for the other two sensitivity simulations are provided in Fig. 16 of the Supplement. Both show differences not exceeding $\pm 5 \%$ (with slightly more importance for the Insol simulation) with mostly low statistical significance, indicating that the ageing is hardly affected by additional compounds in the aerosol phase (Aerchem), and only slightly impacted by the chemical ageing already starting in the hydrophobic Aitken mode due to the low contribution of 
the small particles in a mass weighted mean oxidation state. For this simulations only over tropical oceans and Southern Asia the difference are between 5 and $10 \%$ and the significance level is reached, such that this additional ageing results mainly from the shorter atmospheric residence time (in agreement with the budget calculations from Fig. 2).

A more detailed comparison with observations is performed with the data set presented by $\mathrm{Ng}$ et al. (2010). For some stations a relatively good agreement is obtained, but the results de- viate substantially for other cases. One tendency of the model is to underestimate the high $\mathrm{O}: \mathrm{C}$ ratio values, both in industrialised and remote regions of Europe, North America and East Asia. Figure 4 shows this comparison of the simulated data (red symbols) with observed values (blue symbols) for the average OOA (oxygenated organic aerosol). Since the observation data is from various years and only one year is used for the simulation the correct meteorological conditions for the individual campaigns are not reproduced. Nevertheless, the dates of the campaigns (as provided in the Supplement Ng et al., 2010) are selected for the comparison of observation and model, with the latter sampled at the stations location (including a linear interpolation algorithm). Given the large grid box size including local conditions which cannot be captured by the model grid cells and the strong diurnal variability (as seen in the time series of the O:C ratio provided in the Supplement), this comparison should be regarded more under qualitative than quantitative aspects. An estimate for the temporal variability is marked by the error bars, representing the temporal $1 \sigma$ range during the campaign duration. The analysis from $\mathrm{Ng}$ et al. (2010) also shows that there is a huge range of $\mathrm{O}: \mathrm{C}$ ratios depending whether low- or semi-volatile organic aerosol is measured. The model formulation of the different OC compounds can be translated to also cover a similar range, with the low O:C ratio tracers resembling SV-OOA and those with a high O:C ratio $\mathrm{LV}-\mathrm{OOA}$, such that the mean $\mathrm{O}: \mathrm{C}$ ratio of the total aged organic aerosol is described. The simulated data provide a good representation for the lower O:C ratios, whereas for the observations of highly oxidised organic aerosol the agreement is not captured. Even though the model shows a similar tendency in increasing values as the observations, the magnitude cannot be reproduced. This partly results from the model formulation not allowing higher oxidation states than 0.7 , such that in the mean oxidation state those values can only be reached after maximum oxidation time with no influence of any freshly emitted organic aerosol. The O:C ratios of above 0.7 have been neglected, since the corresponding $\kappa$ values for higher $\mathrm{O}: \mathrm{C}$ ratios have not been reported and a linear interpolation to higher values might not be valid. However, e.g. for Finokalia the model values exceed 0.625 stating that basically all organic carbon is represented by the highest oxidation state tracer. $\mathrm{Ng}$ et al. (2010) report maximum O:C ratios for certain types of organics exceeding 1.0, which then in the mean can substantially increase the observed values above the simulated ones.
One aspect to consider is that generally the model underpredicts the O:C ratio during winter time. This points to the fact that the oxidation might not only be driven by $\mathrm{OH}$ with its maximum production rate at the observation sites in boreal summer, but potentially also by compounds which exhibit their maximum during winter time. One possible compound would be $\mathrm{SO}_{2}$ and its catalysing capacities as proposed by Spracklen et al. (2011), since it does not follow such a strong seasonal cycle as the typical oxidants. Alternatively, the oxidant concentrations during winter might be underestimated as well. Two prominent examples are e.g. Tokyo and Zürich, for which the model matches the observations well during summer (within the variability), but substantially underestimates the $\mathrm{O}: \mathrm{C}$ ratio values during winter time. Also the low simulated values in Reiden originate from winter time data points, where the model substantially underestimates the oxidation state.

Furthermore, a more detailed description of the primary and secondary emissions would be required to explain e.g. the extremely high values reported for Houston and Manchester, i.e. if those emissions contribute very high O:C ratios already at the emission stage, this cannot be reproduced with our simplified scheme.

For the remote regions it can also play a role whether biogenic aerosols could have been underestimated at emission stage, such that the remote stations which are less influenced by aged anthropogenic and more by fresh biogenic organic aerosol result in underestimated values. However, in comparison with data from Amazonia a higher biogenic O:C ratio would result in worse agreement in those regions. However, this requires more laboratory and field data, e.g. if the oxidation capacity would have been known together with the O:C ratios along the atmospheric transport pathways, a better parameterisation could have been developed.

Nevertheless, the qualitative agreement with observations is encouraging given the simplified nature of the parameterisation which does not resolve the detailed chemical reactions involved in the aging process.

As the $\mathrm{O}: \mathrm{C}$ ratio of the aerosol increases with aging so too does the hygroscopicity value $\kappa$ (Petters and Kreidenweis, 2007), as shown by Jimenez et al. (2009). Consequently, more aged organic aerosol will contribute more to the aerosol water uptake. This dependence is seldom accounted for in global models, which typically assume a constant $\kappa_{\mathrm{ORG}}$ value (e.g., Wex et al., 2009; Pöschl et al., 2010). This is the approach adopted in the No-Ageing scenario where a $\kappa_{\mathrm{ORG}}$ value of 0.1 is assumed. To provide an estimate for the organic kappa, the results from the Ageing- $B G$ simulation are shown in Fig. 5 as the organic $\kappa$ sampled at the height of the boundary layer (and then determining the annual average), which is a typical cloud formation altitude. For comparison with the No-Ageing case the constant value of 0.1 is marked by the sharp transition in the colour scale from green to yellow. This threshold marks regions in which the alternative 


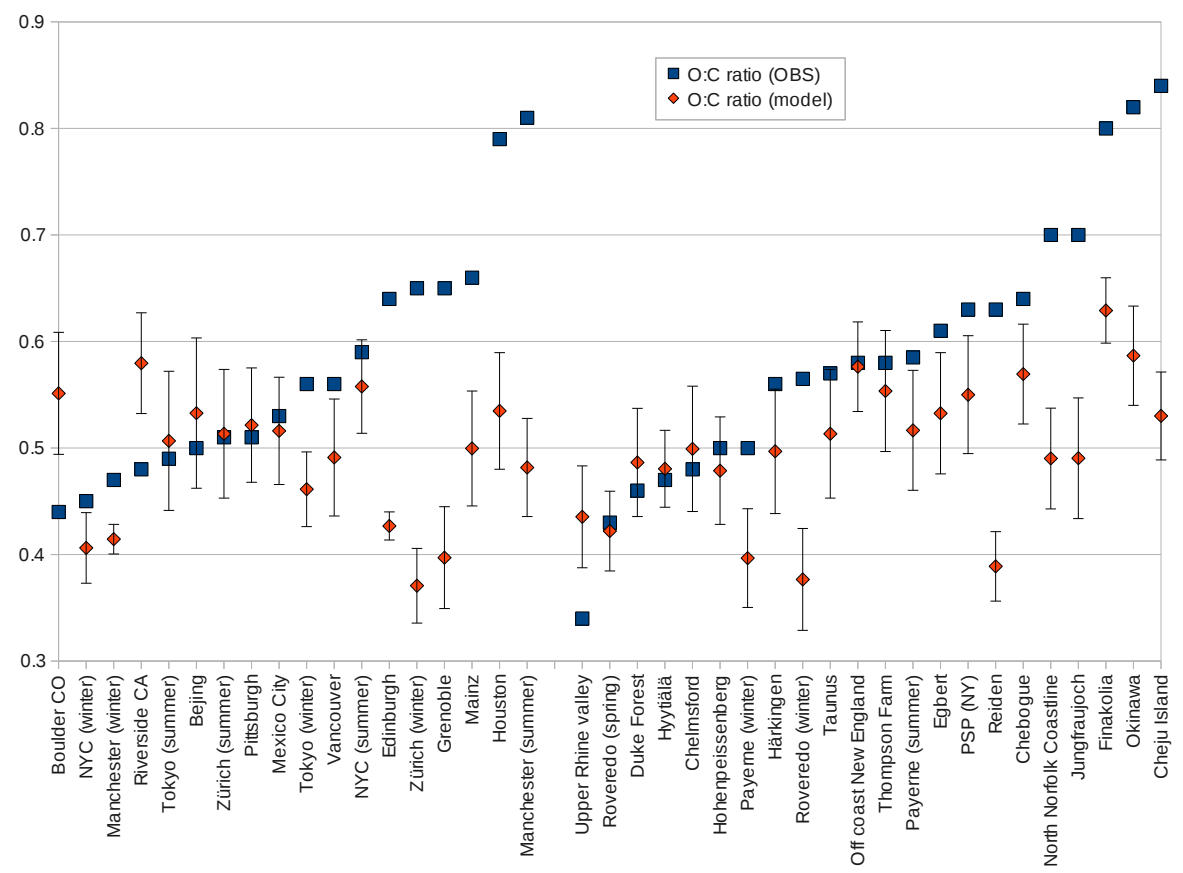

Fig. 4. Comparison of the simulated $\mathrm{O}: \mathrm{C}$ ratios in the surface layer and a collection of observed O:C ratios from various measurement campaigns using different methods and instruments collected and described by $\mathrm{Ng}$ et al. (2010). The blue symbols denote the observed values and the red symbols the simulated mean values during the period of the campaign sampled at the station location. Note, that due to the limited simulation period, the exact year of the observations is not reproduced explaining some of the deviations. The error bars denote the temporal model standard deviation $( \pm 1 \sigma$ range $)$.

a) $\kappa$ at PBL height in the Ageing-BG simulation

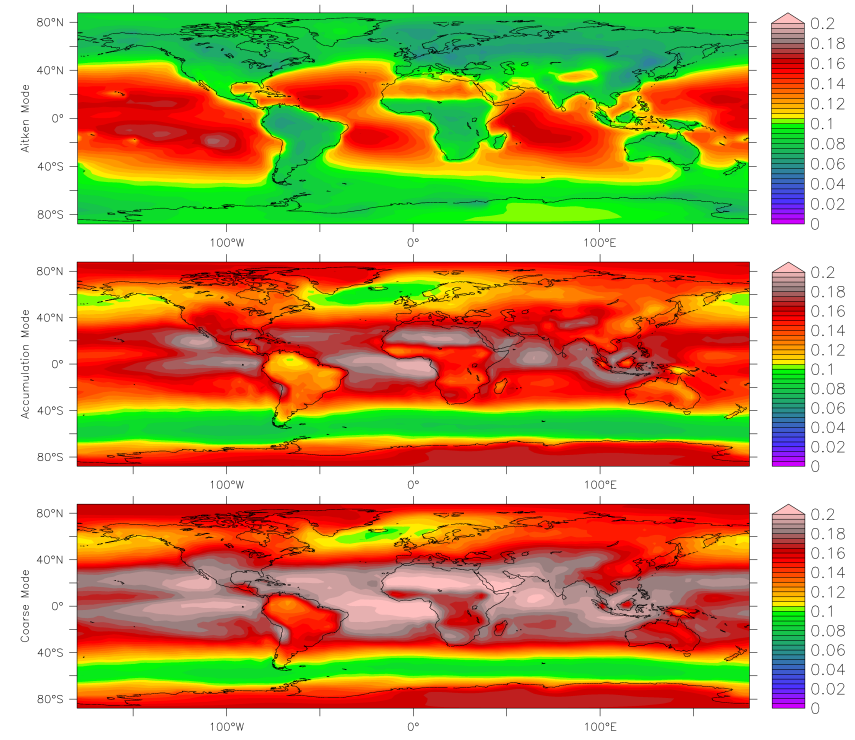

b) Relative difference of the Ageing- $L O$ simulation to Ageing-BG

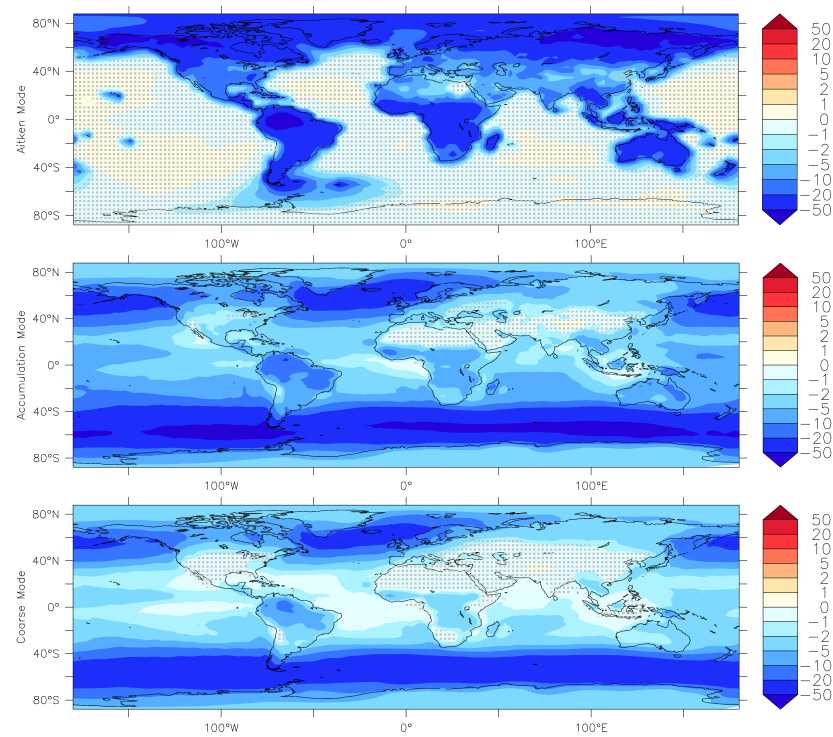

Fig. 5. Annual averages of the organic $\kappa$ for the Ageing-BG simulation at the height of the planetary boundary layer (PBL) (a). The individual panels represent the three larger hydrophilic aerosol modes: Aitken, accumulation and coarse mode (from upper to lower panels). (b) displays the relative difference of the Ageing-LO simulation to the Ageing-BG scenario ("Ageing-LO" - "Ageing-BG")/“Ageing-BG" · 100 in \% for the three modes. The dotted regions are those in which the differences are of low statistical significance. 
description of OC and its chemical ageing leads to increased or reduced $\kappa$ values.

For the hydrophilic Aitken mode (upper panel) most continental regions are characterised by a lower $\kappa$ value, i.e. the relatively freshly emitted organic carbon is less hygroscopic than assumed in the No-Ageing simulation. However, over the oceans a substantial increase in hygroscopicity is observed, except for the subpolar regions in the high latitudes. For most regions the differences are statistically highly significant.

For the accumulation mode in almost all regions a substantial increase is found often exceeding a $50 \%$ increase threshold, except for the storm tracks in the Southern Ocean in which due to the low $\mathrm{OH}$ mixing ratios hardly any ageing occurs. However, material reaching Antarctica has long enough residence times, that also an increase in the hygroscopicity is simulated.

These characteristics are even more pronounced for the coarse mode, resulting in a more than $100 \%$ increase in the organic $\kappa$ over the tropical oceans and the desert regions. Also for the tropical continents a significant increase in the $\kappa$ value has been calculated resulting in a higher potential activation of the organic aerosols into cloud droplets. Especially for the coarse mode, but also for the accumulation mode this increase in $\kappa$ for the organic aerosol is not only an effect of the $\mathrm{OH}$ concentrations, but also of the general age of the aerosol particles. Since the microphysical processing requires a certain amount of time before the aerosol particles grow due to condensation and coagulation, they are naturally longer affected by the $\mathrm{OH}$ exposure and encounter more ageing.

The right column of Fig. 5 shows the relative difference between the Ageing- $L O$ simulation (where the organic carbon is emitted completely into the lowest O:C category) and the Ageing-BG scenario. Especially for the Aitken mode, the continents are subject to a substantial and significant decrease in the organic $\kappa$ in the Ageing-LO scenario, whereas over the oceans the differences are mostly small and largely insignificant. For the accumulation mode, the differences over the continents become smaller (around 10\%), but they are still significant in some regions e.g. South America. The substantial decrease in $\kappa_{\mathrm{ORG}}$ in the Ageing- $L O$ scenario in the Southern Ocean results from the different emission assignment of organic compounds emitted from the ocean. In the coarse mode the differences become even smaller due to the longer atmospheric residence time, such that the large differences originating from the emission attribution reduce to a few $\%$ in the coarse mode $\kappa_{\mathrm{ORG}}$ value, with little statistical significance over most continents, whereas over the oceans the influence from the accumulation mode emission attribution is transferred into the coarse mode via microphysical aerosol ageing and cloud processing. The substantial differences between the two scenarios can directly be related to the emission assignment. However, one has to note, that over the oceans the organic aerosol and therefore the organic $\kappa$ is of minor importance, since sea salt dominates the aerosol population and its hygroscopicity.

The other two simulations (Aerchem and Insol) show smaller deviations, the corresponding figures are presented in the Supplement (Fig. 17). For the Aerchem experiment the simulated fields of $\kappa_{\mathrm{ORG}}$ are very similar to those in the Ageing-BG scenario since the additional uptake does not contribute to the hygroscopicity as it accounts for dissolved material. Consequently, the differences are below any statistical significance. For the Insol simulation the largest differences occur in the hydrophilic Aitken mode. This results from the additional treatment of the hydrophobic, freshly emitted and not microphysically aged organic carbon from mostly anthropogenic sources. The strongest effects are seen over the ocean due to the higher $\mathrm{OH}$ mixing ratios that arise in marine regions because there are fewer competing oxidation reactions. For the larger modes the differences become smaller and less significant because they are affected by microphysical aging in addition to the chemical ageing and both these processes can convert material from the hydrophobic to hydrophilic size modes.

Compared to observations it is difficult to judge which scenario is more realistic; e.g. the mass weighted global mean organic $\kappa$ value for the accumulation mode is around 0.1 in the Ageing- $L O$ scenario. However, especially for the fine mode aerosol in South America a value of 0.15 as found by Pöschl et al. (2010) can only be obtained with the Ageing$B G$ model configuration. Especially, for the tropical continents the low $\mathrm{OC} \kappa$ values obtained in the Ageing- $L O$ simulation underestimate most observations. However, note that the assumption of the linear relation of $\mathrm{O}: \mathrm{C}$ ratio and $\kappa_{\mathrm{ORG}}$, also differs from data set to data set, e.g. the $\kappa_{\mathrm{ORG}}$ of Pöschl et al. (2010) would correspond to a larger O:C ratio than reported in their study. The $\mathrm{O}: \mathrm{C}$ ratios reported by $\mathrm{Ng}$ et al. (2010) mostly exceed the simulated values which corresponds to an even more enhanced value for $\kappa_{\mathrm{ORG}}$ than obtained from the model. Consequently, a mass weighted value of $\kappa_{\mathrm{ORG}}=0.1$ should be at least adjusted to slightly higher values of $\kappa_{\mathrm{ORG}} \approx 0.14$. Nevertheless, for $\mathrm{CCN}$ properties of the aerosol it is also necessary to take the size distribution into account. Even though the mass weighted value of $\kappa_{\mathrm{ORG}}$ might be higher than previously estimated, a lot of small aerosol particles - dominated by the organic fraction in terms of composition - are characterised by a lower oxidation state and hence lower $\kappa_{\mathrm{ORG}}$ values, resulting in less efficient activation potential when compared to a constant $\kappa_{\mathrm{ORG}}$ of 0.1 .

\section{3 "Organic" aerosol water}

The differences in the hygroscopicity of the organic aerosol directly affects the mass of water which can be taken up by the organic compounds and thus affects the total aerosol water following the ZSR rule (Stokes and Robinson, 1966). Since most microphysical and loss processes are influenced by the ambient aerosol size, i.e. the wet diameter, the organic 
a) Organic aerosol water column burden in Ageing$B G$

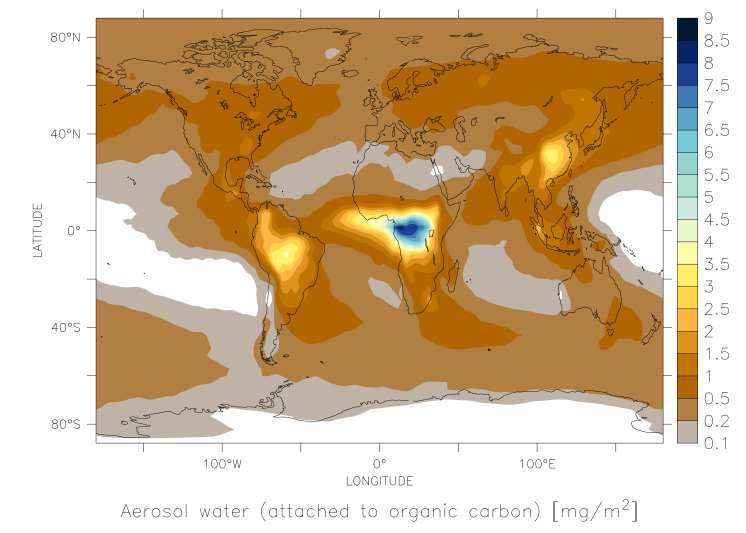

c) Relative difference of the organic aerosol water column burden of No-Ageing to Ageing-BG

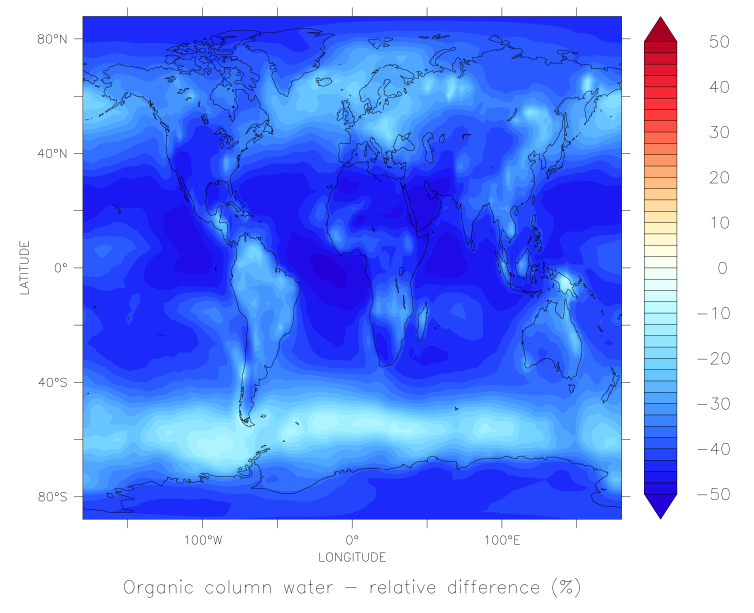

b) Relative contribution to total aerosol water in Ageing- $B G$

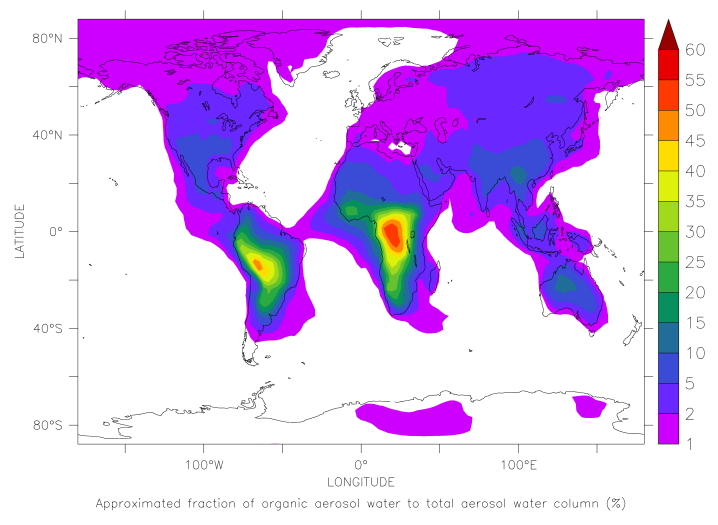

d) Relative difference of the organic aerosol water column burden of Insol to Ageing-BG

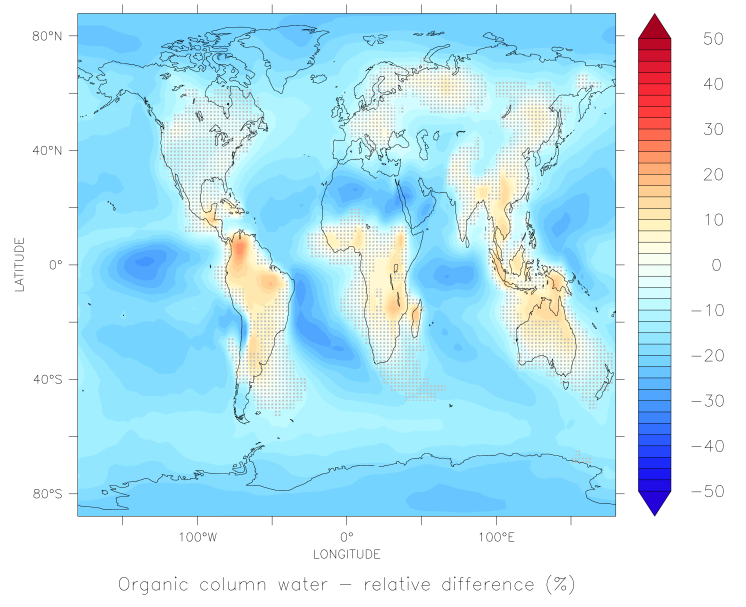

Fig. 6. Annual averages of the organic aerosol water column burden (in $\mathrm{mg} \mathrm{m}^{-2}$ ) for the Ageing-BG simulation (panel a). Note the logarithmic scale. (b) shows the relative contribution (in \%) to the total aerosol water column burden for the respective column. Also note the irregular color scale. (c) and (d) display the relative differences of the No-Ageing and Insol simulations to the Ageing-BG scenario in \%; dotted areas mark regions of low statistical significance.

aerosol hygroscopicity also impacts the aerosol size distribution. This section deals only with the fraction of the aerosol water attracted by the organics; for total aerosol water uptake we refer to a previous study (Pringle et al., 2010b).

Figure 6 displays in panel (a) the column burden of aerosol water attached to the organic aerosol in the Ageing- $B G$ simulation. The regions with largest organic aerosol water are the tropical continents (due to biogenic emissions and biomass burning), South East Asia due to anthropogenic, biomass burning and biogenic emissions and to a lesser extent North America. The oceanic regions hardly contribute to organic aerosol water, except for transported organic aerosol outflow westwards of Africa. This pattern is to a large extent similar to the total organic column burden (see Fig. 1 in the Supple- ment). The organic $\kappa$ value plays a secondary role such that even regions with lower $\kappa_{\mathrm{ORG}}$ have high water uptake due to OC when the OC burden is large.

An example for this can be seen in Amazonia, which is characterised by a relatively high organic $\kappa$ value (cf. Fig. 5a) but there is less organic aerosol water due to the lower OC burden compared to Central Africa.

The upper right panel of Fig. 6 shows the relative contribution of the organic aerosol water to the total aerosol water. This illustrates that in Central Africa and and in Central South America (and to a lesser extent also South of the Sahel in Africa) organic aerosol is one of the dominating compounds for water uptake. In regions of mixed pollution from organic and inorganic aerosol the inorganic compounds 
$\left(\left(\mathrm{NH}_{4}\right)_{2} \mathrm{SO}_{4}, \mathrm{NH}_{4} \mathrm{HSO}_{4}\right.$ and $\left.\mathrm{NH}_{4} \mathrm{NO}_{3}\right)$ mostly contribute more to the total aerosol water (e.g., South-East Asia, USA and Europe), whereas in regions additionally influenced by marine aerosol sea salt dominates the aerosol water uptake. In this study dust is treated as completely hydrophobic and similar to black carbon both do not contribute to water uptake.

The panels (c) and (d) represent the relative difference of the organic aerosol water from the No-Ageing and Insol simulations to the Ageing- $B G$ experiment. Since for the larger modes the organic hygroscopicity is significantly higher in Ageing-BG compared to No-Ageing the water attached to the organic aerosol mass is substantially smaller for the latter simulation. Except for the Southern Ocean with its relatively slow chemical ageing, a reduction in the organic aerosol water burden of up to $50 \%$ is calculated when aging is not included; this is statistically significant in all grid boxes. This large change in water associated with $\mathrm{OC}$ is also obvious in the columns for organic aerosol water in Fig. 2, only the Aitken mode with a lower organic water contribution to the total organic aerosol water exhibits larger water uptake for the No-Ageing scenario.

The other three simulations show lower differences compared with the Ageing-BG scenario. For the Insol simulation, values with $\pm 25 \%$ are not exceeded, and statistical significance is mostly limited to oceanic grid boxes due to the longer residence time and associated ageing (low significance is marked by the dotted regions in Fig. 6). The regions characterised with larger differences between Insol and Ageing- $B G$ are mostly marine regions influenced by continental outflow. Therefore, the different water uptake is not only influenced by differences in the organic $\kappa$, but also by potentially more efficient removal processes due to the faster conversion of hydrophobic to hydrophilic modes.

The differences for the other two simulations (Fig. 18 of the Supplement) are substantially smaller $( \pm 10 \%)$, lacking mostly statistical significance. Only for Ageing- $L O$ a significant difference in the organic aerosol water is found in regions influenced by the marine $\mathrm{OC}$ emissions, and due to their low ageing caused by low $\mathrm{OH}$ concentrations, the emissions assignment and corresponding $\kappa_{\mathrm{ORG}}$ values influence the organic water. However, the organic aerosol water plays a negligible role in those regions due to the high hygroscopicity of sea salt dominating total aerosol water.

In the total burden (cf. Fig. 2), all of these differences balance each other and only small differences in the total organic aerosol water are found. Only the No-Ageing scenario shows substantially less water in the two larger size modes, whereas the reduced values of the Insol simulation are caused by the lower total OC burden.

A separation of the total organic aerosol water per mode (corresponding graphs are provided in the Supplement) results in the following table: As expected the accumulation mode contributes with approx. $66 \%$ most of the organic aerosol water, as already seen from Fig. 2. The contribu-
Table 2. Mass weighted contributions (in \%) of the individual hydrophilic modes to the aerosol water attached to the organic aerosol compounds.

\begin{tabular}{lrrr}
\hline & Aitken & Accumulation & Coarse \\
\hline No-Ageing & 1.96 & 66.68 & 31.36 \\
Ageing-LO & 1.01 & 67.51 & 31.49 \\
Ageing-BG & 1.11 & 66.78 & 32.12 \\
Aerchem & 1.10 & 67.11 & 31.8 \\
Insol & 0.69 & 65.86 & 33.48 \\
\hline
\end{tabular}

tions from the Aitken mode are almost negligible. The lower organic aerosol mass in the Insol simulation in the Aitken mode is also represented by the lower contribution to the total aerosol water, whereas the other two modes show a similar contribution to the total. The geographical patterns of the relative contributions are very similar in the simulations and correspond to Fig. $6 \mathrm{a}$.

\subsection{Dissolution of low molecular weight organic compounds in the aerosol phase}

As the aerosol water represents an aqueous phase reservoir for atmospheric trace compounds, species can diffuse into the aerosol particles and go into solution. For organic compounds this is analysed for three relatively soluble compounds, i.e. $\mathrm{HCOOH}, \mathrm{HCHO}$ and $\mathrm{CH}_{3} \mathrm{COOH}$ summed together under the term of ORG. Figure 7a presents the mixing ratio of the sum of these three compounds dissolved in aerosol water of the accumulation and the coarse mode for the surface layer. Due to the low aerosol water content, the other modes are neglected in this study; generally the coarse mode dominates the contributions by more than $80 \%$. The turquoise contour lines also provide the percentage fraction of the total material $\left(\sum \mathrm{ORG}=\mathrm{ORG}_{\mathrm{gas}}+\mathrm{ORG}_{\mathrm{aer}}\right)$ that is dissolved. Due to the distribution of the gaseous compounds, the dissolution takes place mostly in continental tropical regions and the maritime continent.

The second panel of Fig. 7 expands the analysis to the total column burden. Due to the temperature dependency of the Henry's law coefficient the dissolution becomes more efficient with lower temperatures, but the aerosol water decreases with altitude, such that these two effects compete with each other. Nevertheless, up to the mid-troposphere contributions to the $\mathrm{ORG}_{\mathrm{aer}}$ are not negligible. Considering the column burden leads to a slightly different distribution than analysing the surface mixing ratios alone: even though the regions with large uptake onto aerosol are the same, there are subtle changes: South America becomes dominant and the effect in the Northern part of Central Africa is less important than in the more Southern part. Dissolution effects visible in the surface layer in Northern America and on the Arabian peninsula are unimportant for the total column, mainly due to the reduced aerosol water at higher altitude. 
a) Surface mixing ratio of dissolved volatile organics

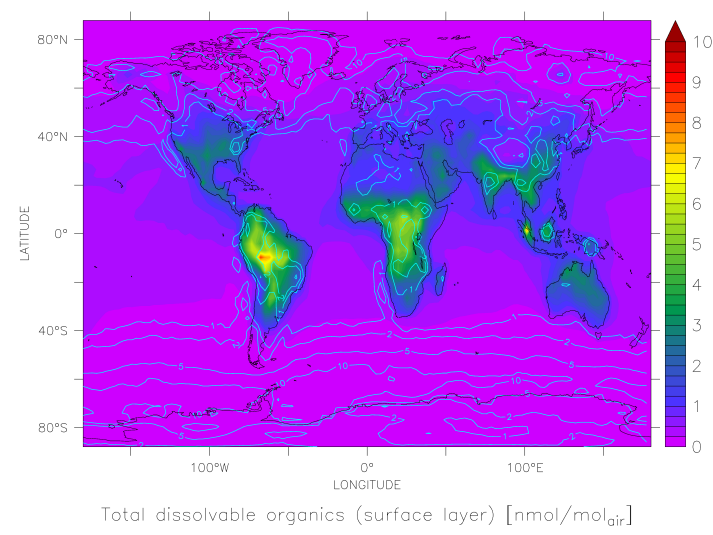

c) Column burden ratio of dissolved to total volatile organics

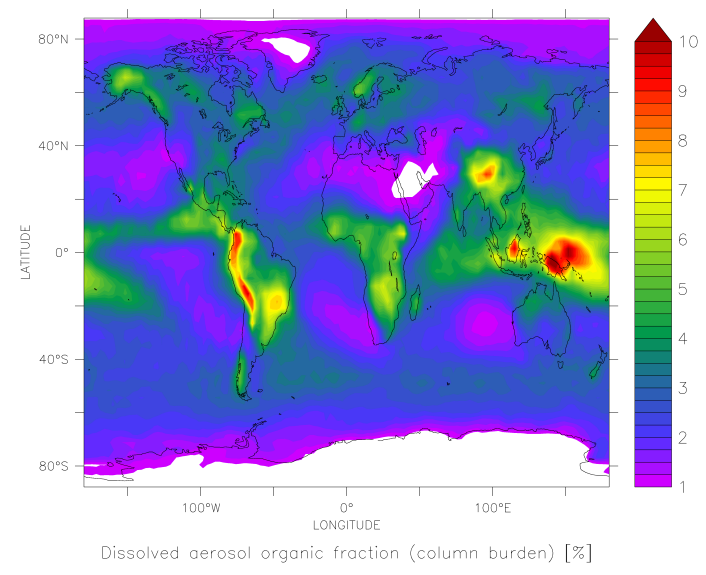

b) Column burden of dissolved volatile organics

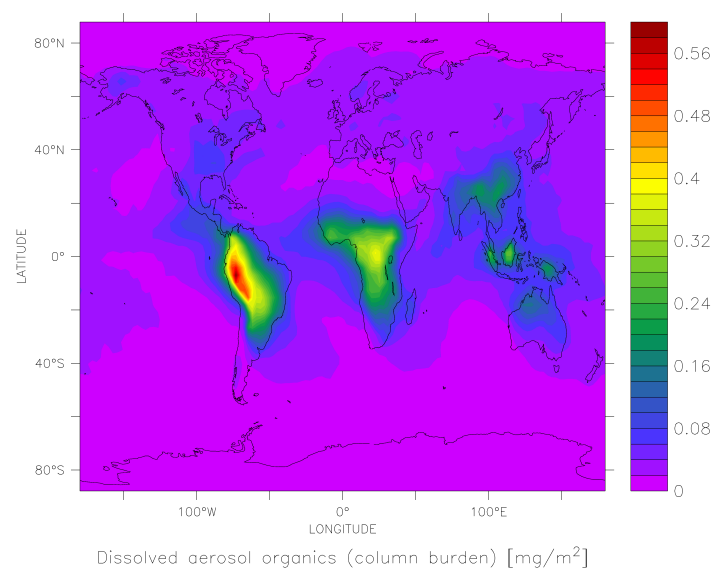

d) Column burden ratio of dissolved to total organic aerosol

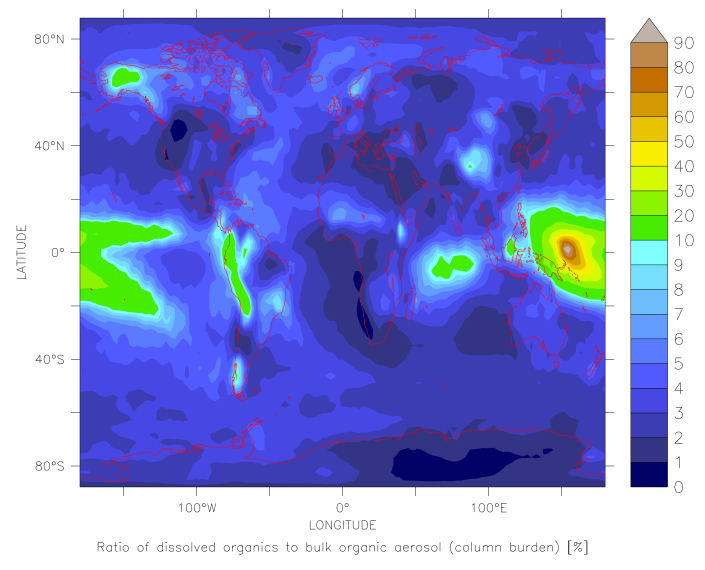

Fig. 7. Panel (a) shows the annual averages of the surface mixing ratio of dissolved volatile organics, namely the sum of $\mathrm{HCHO}, \mathrm{HCOOH}$ and $\mathrm{CH}_{3} \mathrm{COOH}$ in $\mathrm{nmol} / \mathrm{mol}$. The turquoise contour lines represent the relative fraction to the total available sum of those compounds. (b) shows the dissolved organic column burden in $\mathrm{mg} \mathrm{m}^{-2}$. (c) displays the percentage fraction of the total column burden of the sum of the three compounds, whereas in (d) the contribution of the dissolved material to the total organic aerosol (OC and the aged components) is presented. Note the different color bars and sometimes non-linear scales.

The total dissolution efficiency in the column load $\left(\mathrm{ORG}_{\mathrm{aer}} / \sum \mathrm{ORG} \cdot 100\right.$ in \%) is shown in Fig. 7c. It shows that along the Western coast of South America this fraction exceeds $10 \%$, such that the uptake and dissolution of these soluble organics is not negligible. Similar fractions are obtained over the maritime continent and South-East Asia and to a lesser extent in the Southern part of Central Africa. In Europe and the USA the fraction does not exceed 5\%, suggesting that the consideration of this process is of minor importance; this is due to lower total ORG mixing ratios and due to less efficient uptake into the aerosol phase.
Finally, Fig. 7d brings this process into context by comparing the amount of dissolved organic (ORG) to the burden of the "traditional" organic aerosol. In most continental OC source regions the contribution of the dissolved ORG is relatively small. However, the importance of dissolved material increases with increasing atmospheric residence time. This is most prominent over the tropical warm pool, where up to $90 \%$ of the total organic aerosol originates from dissolved compounds, but has also some relevance over other regions, e.g. along the South American West coast. On the other hand it should be kept in mind that the presented compounds are 
generally restricted to the tropics and that in most of the regions identified to be of importance for this process the total "traditional" organic aerosol mass is relatively low resulting in large relative effects and contributions.

In this study the uptake of methanol $\left(\mathrm{CH}_{3} \mathrm{OH}\right)$ has been neglected due to its lower solubility $(\approx$ one order of magnitude smaller Henry's law coefficient than acetic acid, which additionally can dissociate in aerosol $\mathrm{pH}$ value regimes above 4). However, since the gas phase mixing ratios can exceed those of the other considered compounds by up to a factor of 5 the dissolution of this compound may have some impact. This, as well as the impact of glyoxal and other semi-volatile compounds and their aqueous phase production (e.g., Ervens et al., 2011), will be analysed in a following study.

\subsection{Impact on aerosol optical thickness}

Aerosol water is one of the dominating compounds for aerosol optical depth (AOD) (e.g., Pozzer et al., 2012), thus the treatment of the OC may affect the AOD. Figure 8 displays the annual average AOD values in the Ageing- $B G$ experiment. Overall the simulated AOD distribution reproduces the global mean features; the dust sources of the Sahara dominate the regime of high values. A second maximum is found in the polluted regions of China, whereas Europe, the US East coast and also India are characterised by medium values. The contribution from sea salt in oceanic regions usually does not exceed values of 0.2 . The overall distribution looks similar to the annual average observations derived from MODIS and MISR both with respect to the patterns and the magnitude. A more detailed analysis of the AOD values is presented in de Meij et al. (2011).

The panels in the lower row of Fig. 8 show relative differences of two of the sensitivity simulations, whereas the graphs for the other two are found in the Supplement. Even though the aerosol water associated with organic carbon is substantially lower in the No-Ageing simulation compared to Ageing-BG (see Fig. 6c), the total AOD is only slightly affected with hardly any statistical significance over much of the globe (in this figure the regions with statistical significance are marked with a dotted pattern). Only in Central Africa, the region mostly dominated by the organic carbon contribution of the aerosol as analysed above significant differences of up to 10 percent are found. The enhanced water uptake leads to a slightly higher scattering. On the other hand, over the maritime continent, the additional aerosol water and its interaction with other aerosol compounds leads to a slightly reduced OC and more important particle number burden, such that the total extinction, which is already quite small, is even reduced by a few percent. The low sensitivity of the AOD to the aging of the OC is due to the fact that aging produces the largest changes in the organic aerosol water over the ocean where the AOD is low and where the organic fraction of the aerosol water has only a reduced importance for the total aerosol water (see Fig. 6b).
Table 3. Global mean AOD for the five simulations.

\begin{tabular}{lr}
\hline & AOD \\
\hline No-Ageing & 0.1881 \\
Ageing-LO & 0.1892 \\
Ageing-BG & 0.1869 \\
Aerchem & 0.1869 \\
Insol & 0.1791 \\
\hline
\end{tabular}

Furthermore, Fig. $6 \mathrm{c}$ also shows that the smallest relative changes in organic aerosol water are over the ocean due to the lower OC burden in those regions. Since the organics in Africa originate to a large extent from biomass burning and exhibit a strong seasonality, the picture in the annual average smoothes out, seasonal averages depict even stronger patterns (not shown). The Insol simulation shows a statistical significant reduction over the whole tropics. This is due to the lower organic aerosol burden, reducing the extinction. Additionally, the interaction with other aerosol compounds also alters the size distribution (less coagulation due to a more efficient wet removal), such that even though the remaining particles are slightly larger, there are less particles than in the Ageing-BG scenario (not shown), reducing the total extinction.

The Ageing- $L O$ simulation (see Fig. 19 of the Supplement) shows only slight deviations from Ageing- $B G$; except for the maritime continent none are statistically significant. For the Indonesian region the difference results from similar reasons as for the No-Ageing case. Similarly, in Aerchem the differences are below $\pm 2 \%$ lacking statistical significance; even though the additionally treated aerosol compounds (both inorganic and organic) slightly contribute to the extinction, this effect is not important as they do not influence the total aerosol water. The total global mean AOD is listed in the table below, but shows only small influence: the difference between the minimum and maximum of the simulations is less than $5 \%$.

Whether the change in extinction and other aerosol properties is relevant for climate aspects especially in specific regions where the differences are slightly larger, e.g. in Central Africa, will be illuminated in an upcoming study, requiring the full interactive coupling of aerosols, radiation and heating rates.

\subsection{Impact on cloud properties}

To analyse the potential impact of chemical organic aging on cloud properties the cloud condensation nuclei (CCN) concentration at the height of the boundary layer is calculated for all scenarios. A reference supersaturation of $0.4 \%$ is assumed in the CCN calculation, as described in Pringle et al. (2010b). We choose to examine CCN at the height of the planetary boundary layer (PBL) as it is at this level that clouds typically form, thus it is generally representative of 
a) AOD in the Ageing- $B G$ experiment

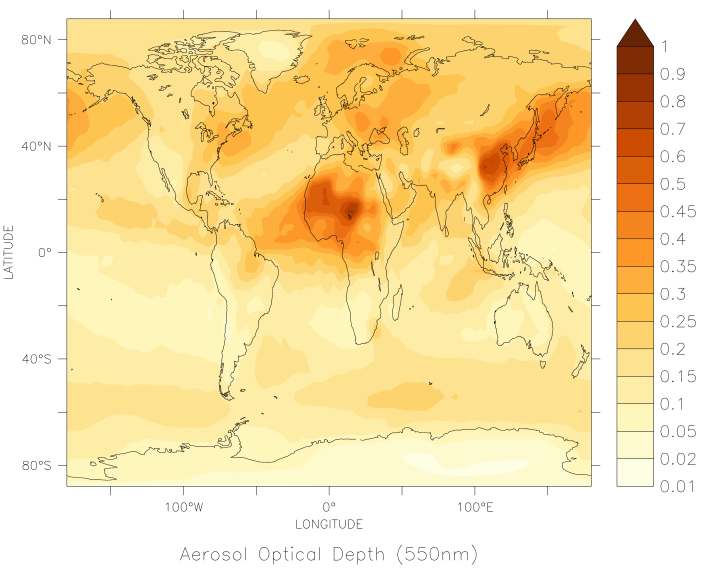

b) Relative difference in the AOD of No-Ageing c) Relative difference in the AOD of Insol compared compared to Ageing-BG to Ageing- $B G$
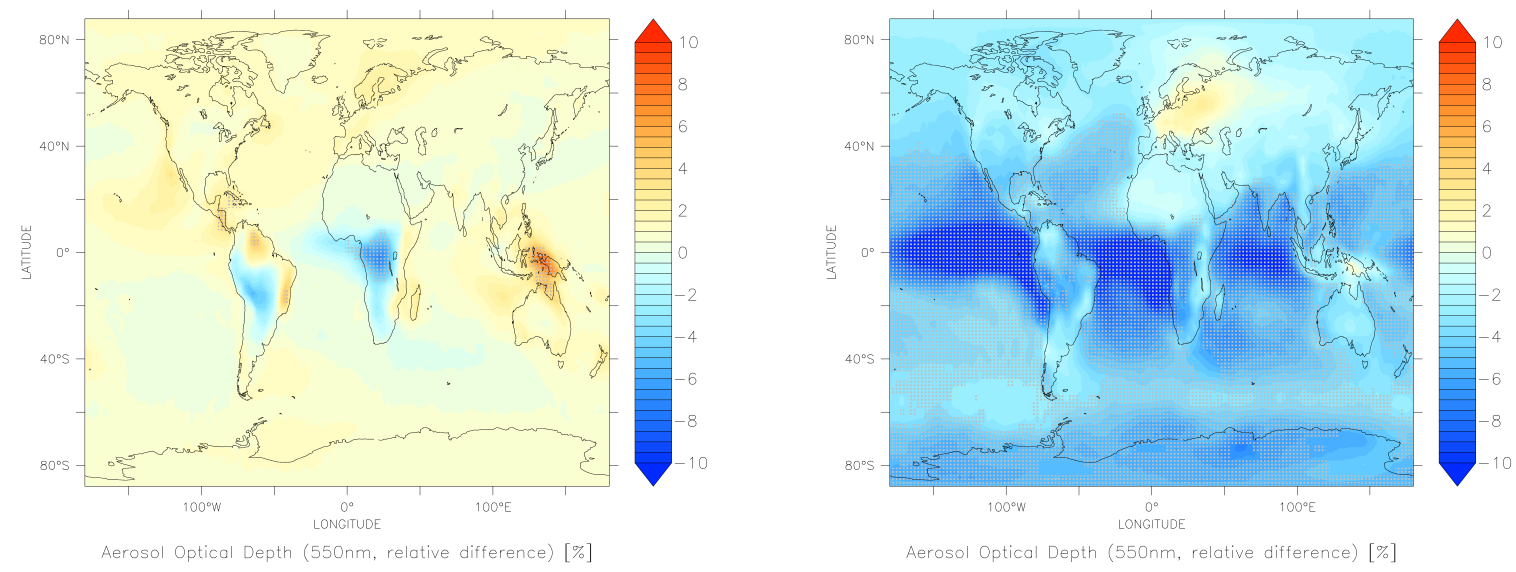

Fig. 8. Annual averages of the total aerosol optical thickness at a wavelength of $550 \mathrm{~nm}$. Panel (a) presents the absolute value for the Ageing$B G$ simulation. The panels (b) and (c) illustrate the relative differences of the No-Ageing and Insol simulations to the reference displayed above. In contrast to previous figures dotted areas mark regions of high statistical significance.

cloud base. The upper left panel of Fig. 9 presents the annual mean CCN concentration at the PBL height. As one would expect, there is a strong land sea contrast in $\mathrm{CCN}$, with some outflow from continental regions, especially over the tropical Atlantic Ocean. Highest CCN values are obtained in Central Africa, India and China co-located with the strongest anthropogenic and biomass burning emissions of organic carbon. Due to their relatively small size at emission, the released mass corresponds to high particle emission number fluxes, which can grow by microphysical and chemical processes until activation into clouds can occur. In most of these regions nucleation of fresh particles plays a minor role due to the energetically preferred condensation processes. In addition to the regions with the highest $\mathrm{CCN}$ values also the biogenic and biomass burning contributions in South America, and the anthropogenic pollution in the Eastern US and
Eastern Europe cause regions with enhanced CCN concentrations.

The comparison with measurements of e.g. Martin et al. (2010), who observe 321 particles per $\mathrm{cm}^{3}$ near the surface in Amazonia in unpolluted periods, provide a good agreement with the simulated values in Ageing-BG of $324 \mathrm{CCN} \mathrm{cm}^{-3}$ in the surface layer and $255 \mathrm{CCN} \mathrm{cm}^{-3}$ at PBL height, even though the meteorological conditions in the observation and simulation period are only the same in the climatological sense. For e.g. outflow from Beijing, Gunthe et al. (2011) report campaign mean values of $1700 \mathrm{CCN} \mathrm{cm}^{-3}$ at $0.7 \%$ supersaturation, and the corresponding model values are $1440 \mathrm{CCN} \mathrm{cm}^{-3}$ in the surface layer and $980 \mathrm{CCN} \mathrm{cm}^{-3}$ at PBL height with the same limits concerning the meteorology, the higher supersaturation in the observations and the 
a) CCN at top of the boundary layer height in Ageing- $B G$
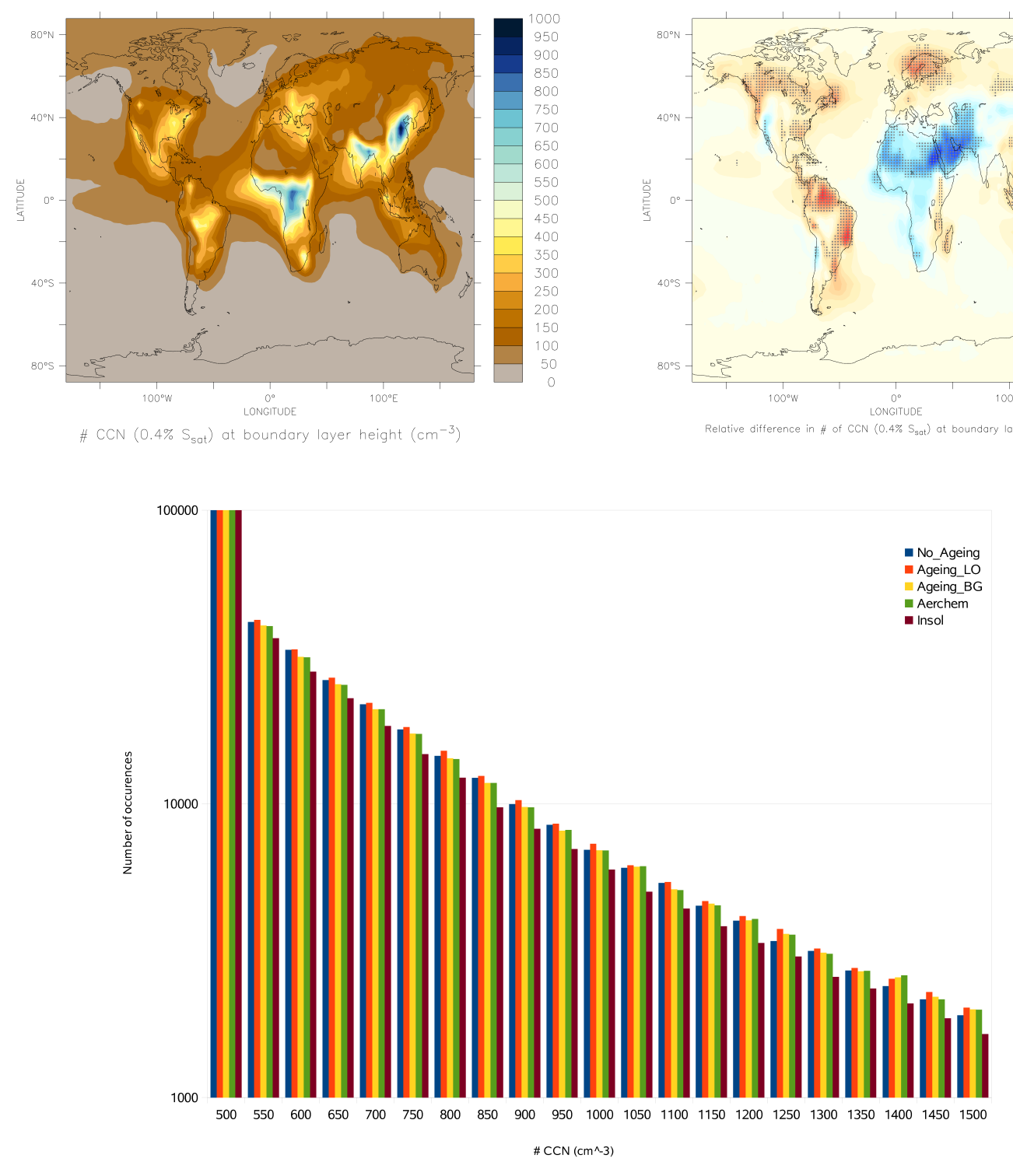

b) Relative difference in the $\mathrm{CCN}$ of No-Ageing compared to Ageing-BG

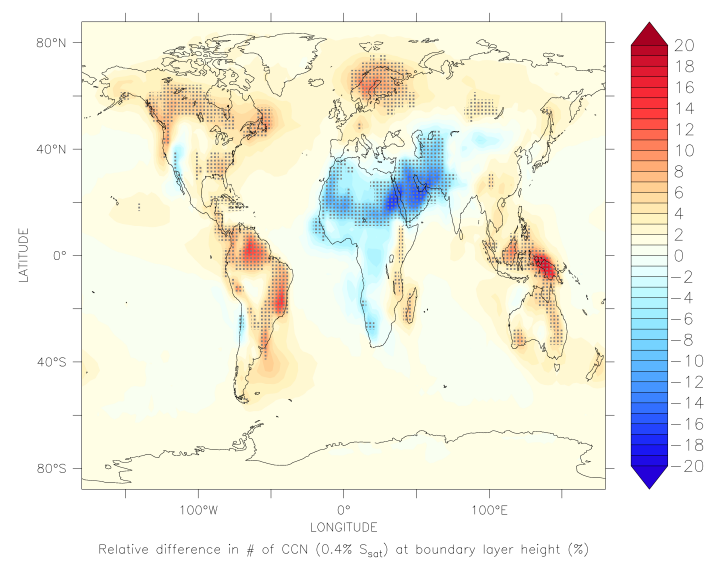

Fig. 9. Annual averages of the total $\mathrm{CCN}$ at the top of the boundary layer height calculated assuming $0.4 \%$ supersaturation. (a) shows the absolute values (in $\#_{\mathrm{cm}^{-3}}$ ) for the Ageing-BG simulation. (b) shows the relative difference to the No-Ageing simulation. The high statistical significance in the differences is marked by the overlayed pattern. The panel in the lower row represents a histogram for the five simulations taking only high $\mathrm{CCN}$ values $\left(>\sim 500 \mathrm{~cm}^{-3}\right)$ into account. The different colours represent the respective simulations.

wide grid mesh of a global model to reproduce local pollution phenomena.

The upper right panel of Fig. 9 analysis the effect of the ageing on cloud droplet activation comparing the No-Ageing with the Ageing- $B G$ simulation. In South America, the maritime continent and Scandinavia statistically significant re- gions with higher $\mathrm{CCN}$ are found in cases in which the ageing is not allowed to take place. In contrast to this the Arabian peninsula and Northern Africa are characterised by higher $\mathrm{CCN}$ in case of ageing. However, in those regions the required supersaturation for activation is only seldom reached. In Central and Southern Africa also higher $\mathrm{CCN}$ values are 
Table 4. Number weighted contributions (in \%) of the individual hydrophilic modes to the total CCN.

\begin{tabular}{lrrr}
\hline & Aitken & Accumulation & Coarse \\
\hline No-Ageing & 4.50 & 93.28 & 2.22 \\
Ageing-LO & 3.99 & 93.82 & 2.19 \\
Ageing-BG & 4.40 & 93.37 & 2.23 \\
Aerchem & 4.28 & 93.48 & 2.24 \\
Insol & 5.14 & 92.52 & 2.34 \\
\hline
\end{tabular}

obtained when ageing is considered, but they are lacking significance, partly due to the high annual variability of the $\mathrm{CCN}$ values. Nevertheless, the differences in some regions can be attributed to the ageing process, e.g. the higher $\mathrm{CCN}$ values in Ageing-BG compared to No-Ageing offshore from the African West coast are most likely a consequence of the higher activation potential of the aged and therefore more hygroscopic organic carbon aerosol originating from Central Africa. The differences for the other simulations are presented in the Supplement. The differences of Ageing- $L O$ and Ageing-BG show a similar pattern as for the No-Ageing case, but with lower values, stating that even though the ageing is allowed, the high oxidation states as in Ageing-BG are not reached. Aerchem shows differences of less than $\pm 2 \%$, resulting only from the minor influence of the additional aerosol compounds on the aerosol size distribution. Insol again is mostly influenced by the lower OC and corresponding particle number burden, such that the higher $\kappa_{\mathrm{ORG}}$ values cannot compensate for the reduction in available particles for activation. Only in the spots in South America, Western Africa and Indonesia the additional OC transferred from the hydrophobic mode can enhance the cloud droplet numbers significantly by up to $15 \%$.

Analysing the contribution of CCNs from the individual modes, a number weighted mean has been calculated and is listed in Table 4.

For the $\mathrm{CCN}$ the number is completely dominated by the accumulation mode. However, especially over the ocean a substantial amount of $\mathrm{CCN}$ originates from the coarse mode, whereas the Aitken mode is mostly only relevant over the oceans due to fine mode sea spray with its high hygroscopicity (figures provided in the Supplement). Freshly emitted organic aerosol of the Aitken mode hardly activates, independent of its ageing state, since chemical and microphysical ageing quickly lead also to growth and hence a shift into the accumulation mode, whereas freshly emitted organic particles are both too small to activate and also have a too low hygroscopicity.

To obtain additional information a histogram of the occurrences of high $\mathrm{CCN}$ values is added in the lower panel of Fig. 9. Only values larger than $500 \mathrm{~cm}^{-3}$ are considered for this analysis, since these values are obtained in regions in which the organic aerosol is a important contributor to the total aerosol population. The low $\mathrm{CCN}$ value spectrum is provided in the Supplement, but shows ambiguous results. For all high CCN values the distributions look similar: Insol has the lowest number of occurrences, this is due to the faster conversion from hydrophobic to hydrophilic modes which reduces the total OC burden and thus also the aerosol number. The second lowest values are obtained by the No-Ageing simulation, in which the $\mathrm{OC}$ contribution to the $\mathrm{CCN}$ is most limited. Ageing- $L O$ is characterised by the highest $C C N$ values, since the ageing process favours increased hygroscopicity and therefore activation potential, but the activation is slower compared to Ageing-BG such that the aerosol particles are subject to slightly smaller sink processes. Ageing$B G$ and Aerchem are intermediates (with almost no differences as also found in Fig. 20c of the Supplement), similar to No-Ageing. In these simulations there is always the competition between more efficient activation due to enhanced hygroscopicity and lower particle numbers caused by more efficient removal processes.

In total the effect on $\mathrm{CCN}$ is relatively small, and only the analysis of the impact of $\mathrm{OC}$ ageing on the radiative properties of the clouds will shed light onto the climate impact of this process, which will be addressed in a follow-up publication.

\section{Conclusions}

This study investigates the impact of a simplified ageing parameterisation organic aerosol without using the full complexity of the 2 dimensional VBS (Jimenez et al., 2009), such that it is suitable for global climate modelling. Even though the processing of the organic aerosol has impacts on the characteristics of the aerosol, the global distribution is not heavily modified, maintaining the agreement with observations obtained from previous studies. Only the additional ageing of the hydrophobic mode organic aerosol, resulting in a conversion into hydrophilic material, substantially alters the organic carbon aerosol distribution, and leads to a substantial reduction in the atmospheric burden of approximately $15 \%$ with substantial implications on radiative and cloud properties. However, this degrades the agreement of model simulation and observations from e.g. the IMPROVE network and must therefore be analysed in more detail whether the representation of the ageing is flawed or the previous agreement with the observations results from compensating errors.

The simulated O:C ratio of the aerosol shows a large variability close to the Earth surface and the emission sources of the organic carbon. With increasing altitude the distribution gets more and more uniform; especially upper tropospheric aerosol is simulated to have a high oxidation state due to its long atmospheric residence time. Comparisons with values obtained from measurement campaigns show a reasonable agreement, especially for the low O:C ratios of the simulated and observed values. The high $\mathrm{O}: \mathrm{C}$ ratios - especially in 
winter time - cannot be reproduced by the model, potentially caused by other oxidants or uncertainties in the O:C ratios at the emission or formation stage of the organic aerosol.

The organic $\kappa$ value derived from the O:C ratio consequently also shows a wide range of values from close to zero to 0.2 , depending on the atmospheric residence time. The simulated values are also in agreement with observations and it should be considered whether a commonly assumed mean organic $\kappa$ value of 0.1 is really suitable for global climate modelling due to the large dependency on particle size and the geographical variability.

Assumptions on details in the ageing process cause only small differences in $\kappa_{\mathrm{ORG}}$, as pointed out by the low statistical significance of the deviations in the sensitivity simulations, especially for larger aerosol particles and after an atmospheric residence time of more than 2 days. The Ageing$B G$ or Aerchem simulations appear to be the most realistic scenarios, compared to ground based field campaigns.

Based on the hygroscopic properties of the aerosol, the water uptake of organics has been discussed, and regions in Central Africa, Australia and South America have been identified in which the water uptake by organics is the dominating effect for total aerosol water. Compared to the situation of a constant water uptake by organic aerosol (No-Ageing), enhanced amounts of aerosol water are calculated with the new ageing parameterisation except for the Aitken mode, in which the on average lower $\kappa_{\mathrm{ORG}}$ values result in a reduced water uptake by freshly emitted organic aerosol. However, this is only important in the regions identified above, since elsewhere more hygroscopic aerosol material dominates the total amount of aerosol water.

Furthermore, a scheme for the additional dissolution of low molecular weight organics in the aerosol water has been developed and applied as a sensitivity test. The outcome of this is, that up to $10 \%$ of the sum of formaldehyde, formic and acetic acid can partition into the aerosol phase in certain regions and a global average of $\approx 4 \%$. For certain regions, especially the tropical warm pool, these compounds contribute to more than $90 \%$ of the simulated total organic aerosol mass. Therefore, this scheme provides also potential for explanation of organic material found in the aerosol phase in remote regions.

The impact of the ageing process on aerosol extinction is found to show relative deviations of only $\pm 10 \%$, caused by the relatively low importance of organic aerosol water to total aerosol water and the modifications in the size distribution. Only changes in the organic aerosol burden and particle number concentrations substantially alter the radiative properties. The magnitude of the effects on the total direct aerosol effect, however, cannot be unambiguously provided at this moment.

The same is valid also for a proxy for the indirect aerosol effect, namely diagnostically calculated $\mathrm{CCN}$ at a fixed supersaturation. Also for the $\mathrm{CCN}$ the differences span up a space of more than $\pm 20 \%$, but with a relatively low statistical significance. The histogram analysis nevertheless points towards an increased CCN distribution for polluted conditions, whereas for remote regions with low $\mathrm{CCN}$ values the result is ambiguous.

The climate impact of the results will be presented in a subsequent study, which allows for full atmospheric climate feedback.

Overall, the representation of the ageing and information on the $\mathrm{O}: \mathrm{C}$ ratio of the organic aerosol provides useful additional information at the expense of relatively low computational extra costs, which can benefit global aerosol chemistry climate simulations by a more accurate process description.

\section{Supplementary material related to this article is available online at: http://www.atmos-chem-phys.net/12/ 8687/2012/acp-12-8687-2012-supplement.pdf.}

Acknowledgements. We thank P. Jöckel and M. Righi for providing the emission data from the respective inventories applied in this study. Furthermore, we thank all MESSy developers and users for support and discussion. Additionally, we thank the DKRZ for their support and the possibility to perform the calculations on computing devices maintained by this institution and the Max Planck Society for their contribution to the calculation time. The graphics of this work have been produced with FERRET, for which we wish to acknowledge: Ferret is a product of NOAA's Pacific Marine Environmental Laboratory (information is available online at http://ferret.pmel.noaa.gov/Ferret/).

Edited by: N. Riemer

\section{References}

Andreae, M. O.: A new look at aging aerosols, Science, 326, 14931494, 2009.

Chang, R. Y.-W., Slowik, J. G., Shantz, N. C., Vlasenko, A., Liggio, J., Sjostedt, S. J., Leaitch, W. R., and Abbatt, J. P. D.: The hygroscopicity parameter $(\kappa)$ of ambient organic aerosol at a field site subject to biogenic and anthropogenic influences: relationship to degree of aerosol oxidation, Atmos. Chem. Phys., 10, 5047-5064, doi:10.5194/acp-10-5047-2010, 2010.

Damian, V., Sandu, A., Damian, M., Potra, F., and Carmichael, G. R.: The kinetic preprocessor KPP - a software environment for solving chemical kinetics, Comput. Chem. Eng., 26, 1567-1579, 2002.

Dentener, F., Kinne, S., Bond, T., Boucher, O., Cofala, J., Generoso, S., Ginoux, P., Gong, S., Hoelzemann, J. J., Ito, A., Marelli, L., Penner, J. E., Putaud, J.-P., Textor, C., Schulz, M., van der Werf, G. R., and Wilson, J.: Emissions of primary aerosol and precursor gases in the years 2000 and 1750 prescribed data-sets for AeroCom, Atmos. Chem. Phys., 6, 43214344, doi:10.5194/acp-6-4321-2006, 2006.

Donahue, N. M., Robinson, A. L., Stanier, C. O., and Pandis, S. N.: Coupled partitioning, dilution, and chemical aging 
of semivolatile organics, Environ. Sci. Technol., 40, 2635-2643, doi:10.1021/es052297c, 2006.

Donahue, N. M., Epstein, S. A., Pandis, S. N., and Robinson, A. L.: A two-dimensional volatility basis set: 1. organic-aerosol mixing thermodynamics, Atmos. Chem. Phys., 11, 3303-3318, doi:10.5194/acp-11-3303-2011, 2011.

Donahue, N. M., Kroll, J. H., Pandis, S. N., and Robinson, A. L.: A two-dimensional volatility basis set - Part 2: Diagnostics of organic-aerosol evolution, Atmos. Chem. Phys., 12, 615-634, doi:10.5194/acp-12-615-2012, 2012.

Ervens, B., Turpin, B. J., and Weber, R. J.: Secondary organic aerosol formation in cloud droplets and aqueous particles (aqSOA): a review of laboratory, field and model studies, Atmos. Chem. Phys., 11, 11069-11102, doi:10.5194/acp-1111069-2011, 2011.

Esaias, W. E., Abbott, M. R., Barton, I., Brown, O. B., Campbell, J. W., Carder, K. L., Clark, D. K., Evans, R. H., Hoge, F. E., Gordon, H. R., Balch, W. M., Letelier, R., and Minnett, P. J.: An overview of MODIS capabilities for ocean science observations, IEEE T. Geosci. Remote, 36, 1250-1265, doi:10.1109/36.701076, 2002. 4381, 4383

Fountoukis, C. and Nenes, A.: ISORROPIA II: a computationally efficient thermodynamic equilibrium model for $\mathrm{K}^{+}, \mathrm{Ca}^{2+}$, $\mathrm{Mg}^{2+}, \mathrm{NH}_{4}^{+}, \mathrm{Na}^{+}, \mathrm{SO}_{4}^{2-}, \mathrm{NO}_{3}^{-}, \mathrm{Cl}^{-}, \mathrm{H}_{2} \mathrm{O}$ aerosols, Atmos. Chem. Phys., 7, 4639-4659, doi:10.5194/acp-7-4639-2007, 2007.

Gunthe, S. S., Rose, D., Su, H., Garland, R. M., Achtert, P., Nowak, A., Wiedensohler, A., Kuwata, M., Takegawa, N., Kondo, Y., Hu, M., Shao, M., Zhu, T., Andreae, M. O., and Pöschl, U.: Cloud condensation nuclei (CCN) from fresh and aged air pollution in the megacity region of Beijing, Atmos. Chem. Phys., 11, 11023-11039, doi:10.5194/acp-1111023-2011, 2011

Hallquist, M., Wenger, J. C., Baltensperger, U., Rudich, Y., Simpson, D., Claeys, M., Dommen, J., Donahue, N. M., George, C., Goldstein, A. H., Hamilton, J. F., Herrmann, H., Hoffmann, T., Iinuma, Y., Jang, M., Jenkin, M. E., Jimenez, J. L., KiendlerScharr, A., Maenhaut, W., McFiggans, G., Mentel, Th. F., Monod, A., Prévôt, A. S. H., Seinfeld, J. H., Surratt, J. D., Szmigielski, R., and Wildt, J.: The formation, properties and impact of secondary organic aerosol: current and emerging issues, Atmos. Chem. Phys., 9, 5155-5236, doi:10.5194/acp-9-51552009, 2009.

Herrmann, H., Tilgner, A., Barzaghi, P., Majdik, Z., Gligorovski, S., Poulain, L., and Monod, A.: Towards a more detailed description of tropospheric aqueous phase organic chemistry: CAPRAM 3.0., Atmos. Environ., 39, 4351-4363, 4351-4363, 2005.

IPCC core writing team: IPCC, 2007: Climate Change 2007: Synthesis Report, Contribution of Working Groups I, II and III to the Fourth Assessment Report of the Intergovernmental Panel on Climate Change, IPCC, Geneva, Switzerland, 2007.

Jimenez, J. L., Canagaratna, M. R., Donahue, N. M., Prévôt, A. S. H., Zhang, Q., Kroll, J. H., DeCarlo, P. F., Allan, J. D., Coe, H., Ng, N. L., Aiken, A. C., Docherty, K. S., Ulbrich, I. M., Grieshop, A. P., Robinson, A. L., Duplissy, J., Smith, J. D., Wilson, K. R., Lanz, V. A., Hueglin, C., Sun, Y. L., Tian, J., Laaksonen, A., Raatikainen, T., Rautiainen, J., Vaattovaara, P., Ehn, M., Kulmala, M., Tomlinson, J. M., Collins, D. R., Cubison, M. J., Dunlea, J., Huffman, J. A., Onasch, T. B., Al- farra, M. R., Williams, P. I., Bower, K., Kondo, Y., Schneider, J., Drewnick, F., Borrmann, S., Weimer, S., Demerjian, K., Salcedo, D., Cottrell, L., Griffin, R., Takami, A., Miyoshi, T., Hatakeyama, S., Shimono, A., Sun, J. Y., Zhang, Y. M., Dzepina, K., Kimmel, J. R., Sueper, D., Jayne, J. T., Herndon, S. C., Trimborn, A. M., Williams, L. R., Wood, E. C., Middlebrook, A. M., Kolb, C. E., Baltensperger, U., and Worsnop, D. R.: Evolution of organic aerosols in the atmosphere, Science, 326, 1525-1529, doi:10.1126/science.1180353, 2009.

Jöckel, P., Kerkweg, A., Buchholz-Dietsch, J., Tost, H., Sander, R., and Pozzer, A.: Technical Note: Coupling of chemical processes with the Modular Earth Submodel System (MESSy) submodel TRACER, Atmos. Chem. Phys., 8, 1677-1687, doi:10.5194/acp8-1677-2008, 2008.

Jöckel, P., Kerkweg, A., Pozzer, A., Sander, R., Tost, H., Riede, H., Baumgaertner, A., Gromov, S., and Kern, B.: Development cycle 2 of the Modular Earth Submodel System (MESSy2), Geosci Model Dev., 3, 717-752, doi:10.5194/gmd-3-717-2010, 2010.

Kanakidou, M., Seinfeld, J. H., Pandis, S. N., Barnes, I., Dentener, F. J., Facchini, M. C., Van Dingenen, R., Ervens, B., Nenes, A., Nielsen, C. J., Swietlicki, E., Putaud, J. P., Balkanski, Y., Fuzzi, S., Horth, J., Moortgat, G. K., Winterhalter, R., Myhre, C. E. L., Tsigaridis, K., Vignati, E., Stephanou, E. G., and Wilson, J.: Organic aerosol and global climate modelling: a review, Atmos. Chem. Phys., 5, 1053-1123, doi:10.5194/acp-51053-2005, 2005.

Kerkweg, A., Buchholz, J., Ganzeveld, L., Pozzer, A., Tost, H., and Jöckel, P.: Technical Note: An implementation of the dry removal processes DRY DEPosition and SEDImentation in the Modular Earth Submodel System (MESSy), Atmos. Chem. Phys., 6, 4617-4632, doi:10.5194/acp-6-4617-2006, 2006a.

Kerkweg, A., Sander, R., Tost, H., and Jöckel, P.: Technical note: Implementation of prescribed (OFFLEM), calculated (ONLEM), and pseudo-emissions (TNUDGE) of chemical species in the Modular Earth Submodel System (MESSy), Atmos. Chem. Phys., 6, 3603-3609, doi:10.5194/acp-6-3603-2006, 2006 b.

Kerkweg, A., Sander, R., Tost, H., Jöckel, P., and Lelieveld, J.: Technical Note: Simulation of detailed aerosol chemistry on the global scale using MECCA-AERO, Atmos. Chem. Phys., 7, 2973-2985, doi:10.5194/acp-7-2973-2007, 2007.

Kroll, J. H., Donahue, N. M., Jimenez, J. L., Kessler, S. H., Canagaratna, M. R., Wilson, K. R., Altieri, K. E., Mazzoleni, L. R., Wozniak, A. S., Bluhm, H., Mysak, E. R., Smith, J. D., Kolb, C. E., and Worsnop, D. R.: Carbon oxidation state as a metric for describing the chemistry of atmospheric organic aerosol, Nature Chem., 3, 133-139, doi:10.1038/nchem.948, 2011.

Lamarque, J.-F., Bond, T. C., Eyring, V., Granier, C., Heil, A., Klimont, Z., Lee, D., Liousse, C., Mieville, A., Owen, B., Schultz, M. G., Shindell, D., Smith, S. J., Stehfest, E., Van Aardenne, J., Cooper, O. R., Kainuma, M., Mahowald, N., McConnell, J. R., Naik, V., Riahi, K., and van Vuuren, D. P.: Historical (1850-2000) gridded anthropogenic and biomass burning emissions of reactive gases and aerosols: methodology and application, Atmos. Chem. Phys., 10, 7017-7039, doi:10.5194/acp10-7017-2010, 2010.

Lelieveld, J., Butler, T. M., Crowley, J. N., Dillon, T. J., Fischer, H., Ganzeveld, L., Harder, H., Lawrence, M. G., Martinez, M., Taraborrelli, D., and Williams, J.: Atmospheric 
oxidation capacity+ sustained by a tropical forest, Nature, 452 , 737-740, doi:10.1038/nature06870, 2008.

Martin, S. T., Andreae, M. O., Althausen, D., Artaxo, P., Baars, H., Borrmann, S., Chen, Q., Farmer, D. K., Guenther, A., Gunthe, S. S., Jimenez, J. L., Karl, T., Longo, K., Manzi, A., Müller, T., Pauliquevis, T., Petters, M. D., Prenni, A. J., Pöschl, U., Rizzo, L. V., Schneider, J., Smith, J. N., Swietlicki, E., Tota, J., Wang, J., Wiedensohler, A., and Zorn, S. R.: An overview of the Amazonian Aerosol Characterization Experiment 2008 (AMAZE-08), Atmos. Chem. Phys., 10, 1141511438, doi:10.5194/acp-10-11415-2010, 2010.

de Meij, A., Pozzer, A., Pringle, K. J., Tost, H., and Lelieveld, J.: EMAC model evaluation and analysis of atmospheric aerosol properties and distribution, with a focus on the Mediterranean region, Atmos. Research, 114-115, 38-69, doi:10.1016/j.atmosres.2012.05.014, 2012

Ng, N. L., Canagaratna, M. R., Zhang, Q., Jimenez, J. L., Tian, J., Ulbrich, I. M., Kroll, J. H., Docherty, K. S., Chhabra, P. S., Bahreini, R., Murphy, S. M., Seinfeld, J. H., Hildebrandt, L., Donahue, N. M., DeCarlo, P. F., Lanz, V. A., Prévôt, A. S. H., Dinar, E., Rudich, Y., and Worsnop, D. R.: Organic aerosol components observed in Northern Hemispheric datasets from Aerosol Mass Spectrometry, Atmos. Chem. Phys., 10, 46254641, doi:10.5194/acp-10-4625-2010, 2010.

O'Donnell, D., Tsigaridis, K., and Feichter, J.: Estimating the direct and indirect effects of secondary organic aerosols using ECHAM5-HAM, Atmos. Chem. Phys., 11, 8635-8659, doi:10.5194/acp-11-8635-2011, 2011.

Petters, M. D. and Kreidenweis, S. M.: A single parameter representation of hygroscopic growth and cloud condensation nucleus activity, Atmos. Chem. Phys., 7, 1961-1971, doi:10.5194/acp-71961-2007, 2007.

Pöschl, U., Martin, S. T., Sinha, B., Chen, Q., Gunthe, S. S., Huffman, J. A., Borrmann, S., Farmer, D. K., Garland, R. M., Helas, G., Jimenez, J. L., King, S. M., Manzi, A., Mikhailov, E., Pauliquevis, T., Petters, M. D., Prenni, A. J., Roldin, P., Rose, D., Schneider, J., Su, H., Zorn, S. R., Artaxo, P., and Andreae, M. O.: Rainforest aerosols as biogenic nuclei of clouds and precipitation in the Amazon, Science, 329, 1513-1516, doi:10.1126/science.1191056, 2010.

Pozzer, A., de Meij, A., Pringle, K. J., Tost, H., Doering, U. M., van Aardenne, J., and Lelieveld, J.: Distributions and regional budgets of aerosols and their precursors simulated with the EMAC chemistry-climate model, Atmos. Chem. Phys., 12, 961987, doi:10.5194/acp-12-961-2012, 2012.

Pringle, K. J., Tost, H., Metzger, S., Steil, B., Giannadaki, D., Nenes, A., Fountoukis, C., Stier, P., Vignati, E., and Lelieveld, J.: Description and evaluation of GMXe: a new aerosol submodel for global simulations (v1), Geosci. Model Dev., 3, 391-412, doi:10.5194/gmd-3-391-2010, 2010a.

Pringle, K. J., Tost, H., Pozzer, A., Pöschl, U., and Lelieveld, J.: Global distribution of the effective aerosol hygroscopicity parameter for CCN activation, Atmos. Chem. Phys., 10, 52415255, doi:10.5194/acp-10-5241-2010, 2010 b.

Robinson, A. L., Donahue, N. M., Shrivastava, M. K., Weitkamp, E. A., Sage, A. M., Grieshop, A. P., Lane, T. E., Pierce, J. R., and Pandis, S. N.: Rethinking organic aerosols: semivolatile emissions and photochemical aging, Science, 315, 1259-1262, doi:10.1126/science.1133061, 2007.
Roeckner, E., Bäuml, G., Bonaventura, L., Brokopf, R., Esch, M., Giorgetta, M., Hagemann, S., Kirchner, I., Kornblue, L., Manzini, E., Rhodin, A., Schleese, U., Schulzweida, U., and Tompkins, A.: The atmospheric general circulation model ECHAM5: Part 1, Technical Report, 349, Max-Planck-Institut für Meteorologie, 2003.

Roeckner, E., Brokopf, R., Esch, M., Giogetta, M., Hagemann, S., Kornblueh, L., Manzini, E., Schleese, U., and Schulzweida, U.: Sensitivity of simulated climate to horizontal and vertical resolution in the ECHAM5 atmosphere model, J. Clim., 19, 37713791, 2006.

Sander, R., Kerkweg, A., Jöckel, P., and Lelieveld, J.: Technical note: The new comprehensive atmospheric chemistry module MECCA, Atmos. Chem. Phys., 5, 445-450, doi:10.5194/acp-5445-2005, 2005.

Sandu, A., Verwer, J. G., Blom, J. G., Spee, E. J., Carmichael, G. R., and Potra, F. A.: Benchmarking stiff ODE solvers for atmospheric chemistry problems - II: Rosenbrock solvers, Atmos. Environ., 31, 3459-3472, 1997.

Schmale, J., Schneider, J., Ancellet, G., Quennehen, B., Stohl, A., Sodemann, H., Burkhart, J. F., Hamburger, T., Arnold, S. R., Schwarzenboeck, A., Borrmann, S., and Law, K. S.: Source identification and airborne chemical characterisation of aerosol pollution from long-range transport over Greenland during POLARCAT summer campaign 2008, Atmos. Chem. Phys., 11, 1009710123, doi:10.5194/acp-11-10097-2011, 2011.

Shrivastava, M., Fast, J., Easter, R., Gustafson Jr., W. I., Zaveri, R. A., Jimenez, J. L., Saide, P., and Hodzic, A.: Modeling organic aerosols in a megacity: comparison of simple and complex representations of the volatility basis set approach, Atmos. Chem. Phys., 11, 6639-6662, doi:10.5194/acp-11-66392011, 2011.

Spracklen, D. V., Jimenez, J. L., Carslaw, K. S., Worsnop, D. R., Evans, M. J., Mann, G. W., Zhang, Q., Canagaratna, M. R., Allan, J., Coe, H., McFiggans, G., Rap, A., and Forster, P.: Aerosol mass spectrometer constraint on the global secondary organic aerosol budget, Atmos. Chem. Phys., 11, 12109-12136, doi:10.5194/acp-11-12109-2011, 2011.

Stokes, R. H. and Robinson, R. A.: Interactions in aqueous nonelectrolyte solutions, I. solute-solvent equilibria, J. Phys. Chem., 70, 2126-2131, doi:10.1021/j100879a010, 1966.

Suda, S. R., Petters, M. D., Matsunaga, A., Sullivan, R. C., Ziemann, P. J., and Kreidenweis, S. M.: Hygroscopicity frequency distributions of secondary organic aerosols, J. Geophys. Res., 117, 148-227, doi:10.1029/2011JD016823, 2012.

Taraborrelli, D., Lawrence, M. G., Butler, T. M., Sander, R., and Lelieveld, J.: Mainz Isoprene Mechanism 2 (MIM2): an isoprene oxidation mechanism for regional and global atmospheric modelling, Atmos. Chem. Phys., 9, 2751-2777, doi:10.5194/acp-92751-2009, 2009.

Taraborrelli, D., Lawrence, M. G., Crowley, J. N., Dillon, T. J., Gromov, S., Groß, C. B. M., Vereecken, L., and Lelieveld, J.: Hydroxyl radical buffered by isoprene oxidation over tropical forests, Nature Geosci., 5, 190-193, doi:10.1038/ngeo1405, 2012.

Taylor, K., Williamson, D., and Zwiers, F.: The sea surface temperature and sea ice concentration boundary conditions for AMIP II simulations, Technical Report, 60, PCMDI, 2000. 
Textor, C., Schulz, M., Guibert, S., Kinne, S., Balkanski, Y., Bauer, S., Berntsen, T., Berglen, T., Boucher, O., Chin, M., Dentener, F., Diehl, T., Easter, R., Feichter, H., Fillmore, D., Ghan, S., Ginoux, P., Gong, S., Grini, A., Hendricks, J., Horowitz, L., Huang, P., Isaksen, I., Iversen, I., Kloster, S., Koch, D., Kirkevåg, A., Kristjansson, J. E., Krol, M., Lauer, A., Lamarque, J. F., Liu, X., Montanaro, V., Myhre, G., Penner, J., Pitari, G., Reddy, S., Seland, Ø., Stier, P., Takemura, T., and Tie, X.: Analysis and quantification of the diversities of aerosol life cycles within AeroCom, Atmos. Chem. Phys., 6, 1777-1813, doi:10.5194/acp-6-1777-2006, 2006.

Tost, H., Jöckel, P., Kerkweg, A., Sander, R., and Lelieveld, J.: Technical note: A new comprehensive SCAVenging submodel for global atmospheric chemistry modelling, Atmos. Chem. Phys., 6, 565-574, doi:10.5194/acp-6-565-2006, 2006.

Tost, H., Jöckel, P., Kerkweg, A., Pozzer, A., Sander, R., and Lelieveld, J.: Global cloud and precipitation chemistry and wet deposition: tropospheric model simulations with ECHAM5/MESSy1, Atmos. Chem. Phys., 7, 2733-2757, doi:10.5194/acp-7-2733-2007, 2007a.

Tost, H., Jöckel, P., and Lelieveld, J.: Lightning and convection parameterisations - uncertainties in global modelling, Atmos. Chem. Phys., 7, 4553-4568, doi:10.5194/acp-7-4553-2007, 2007b.

Tost, H., Lawrence, M. G., Brühl, C., Jöckel, P., The GABRIEL Team, and The SCOUT-O3DARWIN/ACTIVE Team: Uncertainties in atmospheric chemistry modelling due to convection parameterisations and subsequent scavenging, Atmos. Chem. Phys., 10, 1931-1951, doi:10.5194/acp-10-1931-2010, 2010a.
Tost, H., Pringle, K. J., and Lelieveld, J.: The phase dependency of atmospheric sulphate production Poster at the IGAC conference, 2010b.

Tsigaridis, K. and Kanakidou, M.: Global modelling of secondary organic aerosol in the troposphere: a sensitivity analysis, Atmos. Chem. Phys., 3, 1849-1869, doi:10.5194/acp-3-1849-2003, 2003.

Vignati, E., Wilson, J., and Stier, P.: M7: an efficient sizeresolved aerosol microphysics module for large-scale aerosol transport models, J. Geophys. Res., 109, D22202, doi:10.1029/2003JD004485, 2004.

Vignati, E., Facchini, M., Rinaldi, M., Scannell, C., Ceburnis, D., Sciare, J., Kanakidou, M., Myriokefalitakis, S., Dentener, F., and O'Dowd, C.: Global scale emission and distribution of sea-spray aerosol: sea-salt and organic enrichment, Atmos. Environ., 44, 670-677, doi:10.1016/j.atmosenv.2009.11.013, 2010.

van der Werf, G. R., Randerson, J. T., Giglio, L., Collatz, G. J., Mu, M., Kasibhatla, P. S., Morton, D. C., DeFries, R. S., Jin, Y., and van Leeuwen, T. T.: Global fire emissions and the contribution of deforestation, savanna, forest, agricultural, and peat fires (1997-2009), Atmos. Chem. Phys., 10, 11707-11735, doi:10.5194/acp-10-11707-2010, 2010.

Wex, H., Petters, M. D., Carrico, C. M., Hallbauer, E., Massling, A., McMeeking, G. R., Poulain, L., Wu, Z., Kreidenweis, S. M., and Stratmann, F.: Towards closing the gap between hygroscopic growth and activation for secondary organic aerosol: Part $1-$ Evidence from measurements, Atmos. Chem. Phys., 9, 3987-3997, doi:10.5194/acp-9-3987-2009, 2009. 